\title{
Computational biomechanics of knee joint arthroplasty : a review
}

\author{
Kyoung-Tak KANG*, Yong-Gon $\mathrm{KOH}^{* *}$, Jin-Ah LEE* and Heoung-Jae CHUN**** \\ * Department of Mechanical Engineering, Yonsei University, \\ 50 Yonsei-ro, Seodaemun-gu, Seoul, Korea \\ E-mail: hjchun@yonsei.ac.kr \\ ** Joint Reconstruction Center and Department of Orthopaedic Surgery, Yonsei Sarang Hospital, \\ 478-3, Bangbae-dong, Seocho-gu, Seoul, Korea \\ *** Department of Mechanical Engineering, Keio University, \\ 3-14-1 Hiyoshi, Kohoku-ku, Yokohama, Kanagawa, Japan
}

Received: 27 June 2019; Revised: 20 September 2019; Accepted: 23 October 2019

\begin{abstract}
Computational models have been widely used for more than four decades to evaluate the mechanical behavior of knee joint arthroplasty. Validated computational models provide a virtual platform to develop optimal articular surfaces which achieve desired implant characteristics. This review paper provides a comprehensive overview of the computational models available to represent knee joint arthroplasty. A brief overview of knee joint anatomy and arthroplasty is provided, followed by computational model development techniques. Use of the computational models in development of knee joint arthroplasty and pre- or post-clinical evaluation is summarized. This review paper presents current modeling capabilities for implant design and stability, with further suggestions for studying the performance of implants on a population level. However, simulations must include closely corroborated multi-domain analysis in order to account for real-life variability.
\end{abstract}

Keywords : Knee, Computational biomechanics, Total knee arthroplasty, Unicompartment knee arthroplasty

\section{Anatomy of the knee joint}

The knee joint is one of the most important joints in the human body. It allows the lower extremity to move relative to the thigh while supporting the body weight. Knee joint movements are essential to many basic activities such as walking, running, sitting and standing.

The tibiofemoral (TF) joint is a synovial hinge joint formed between three bones: the femur, tibia, and patella. Two rounded convex condyles on the distal end of the femur meet rounded medial concave and lateral convex condyles at the proximal end of the tibia (Freeman and Pinskerova, 2005).

In addition to the TF, the knee also includes the patellofemoral (PF) joint (Fig.1). Together, these joints allow the knee to move in three planes: sagittal, transverse, and coronal. This offers a range of motion in six degrees of freedom, including flexion and extension in the sagittal plane, internal and external rotation in the transverse plane, and varus and valgus stress in the coronal plane. (Fig.2) The position of the knee between the two longest lever arms of the body, the femur and tibia, and its role in weight bearing renders it susceptible to injuries (Abulhasan and Grey, 2017). The jointforming surfaces of each bone are covered by a thin layer of hyaline cartilage, providing an extremely smooth surface for protection of the underlying bone from damage (Buckwalter, 2002). Between the femur and tibia is a figure-eightshaped layer of tough, rubbery fibrocartilage known as the meniscus (Ha et al., 2010; Makris et al., 2011). It acts as a shock absorber inside the knee to prevent the collision of the leg bones during strenuous activities such as running and jumping (Ha, Shim, Kim, Lee, Ra and Kim, 2010; Makris, Hadidi and Athanasiou, 2011).

The knee is stabilized by both primary and secondary stabilizers. Primary stabilization is achieved through ligaments, 


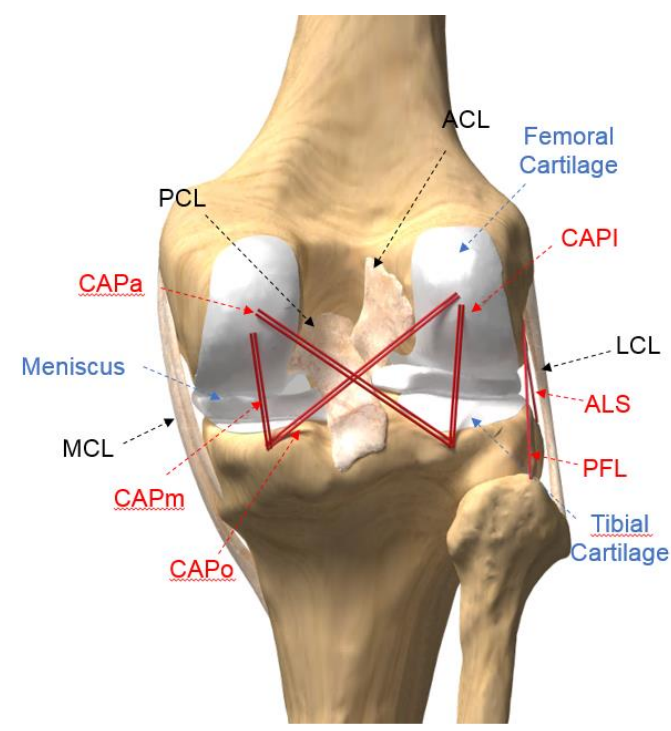

Fig. 1 Anatomy of knee joint: ACL: anterior cruciate ligament; PCL: posterior cruciate ligament; LCL: Lateral collateral ligament; MCL: medial collateral ligament; CAPm, CAPl, CAPo and CAPa: medial, lateral, oblique popliteal and arcuate popliteal bundles of posterior capsule; ALS: anterolateral structure; PFL: popliteofibular ligament.

while muscles around the knee joint play a secondary role, although both work congruently to support the knee function (Abulhasan and Grey, 2017). Ligaments are fibrous bands of tissue that connect one bone to the other to provide support to joints. The knee is reinforced by two collateral ligaments on the medial and lateral sides, as well as two stronger ligaments known as the cruciate ligaments which prevent excessive anterior, posterior, varus, and valgus displacement of the tibia in relation to the femur. The patellar ligament is the inferior continuation of the quadriceps femoris tendon, and attaches proximally to the apex of the patella and distally to the tibial tuberosity. Other ligaments also act as knee stabilizers: the transverse, arcuate popliteal, oblique popliteal, anterior cruciate ligament (ACL), posterior cruciate ligament (PCL), medial collateral ligament (MCL), lateral collateral ligament (LCL), and popliteofibular ligament (Gollehon et al., 1987; LaPrade and Wentorf, 2002). Additional ligaments surround the knee joint to maintain overall knee stability, including the capsular ligament, anterolateral ligament, arcuate ligament, and posterior oblique ligament (Fig.1). All provide stability in a specific direction and play an important role in joint proprioception through their cutaneous receptors.
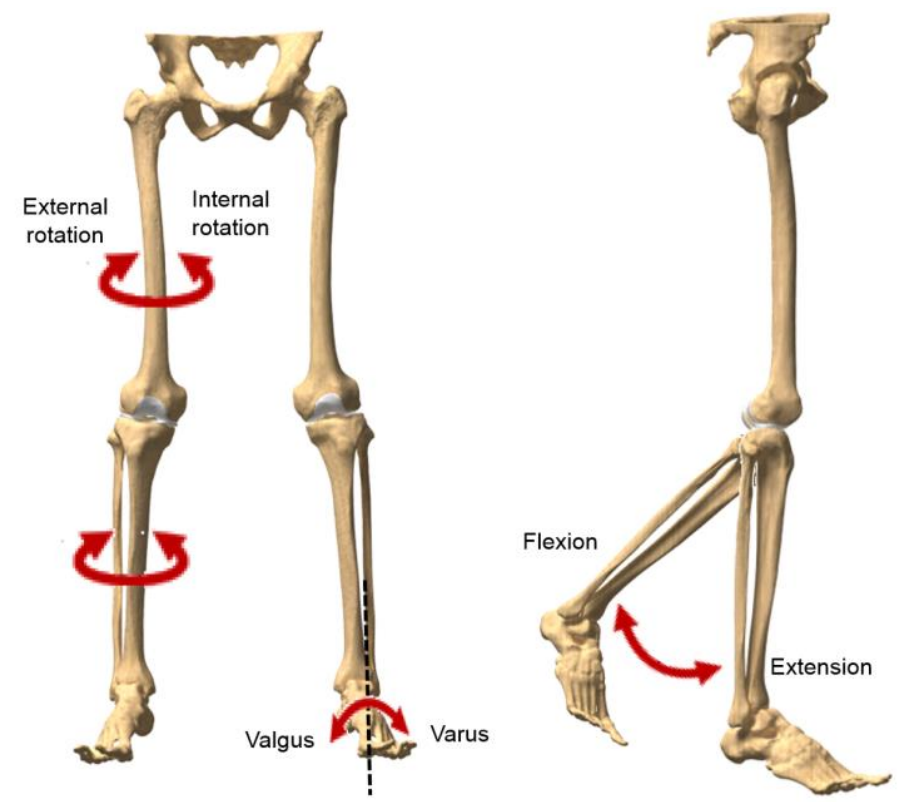

Fig. 2 Diagram showing movements of the knee with six degrees of freedom. 
The secondary stabilizers of the knee consist of the muscles surrounding the knee joint along with the hip and gastrocnemius muscles (Fig. 1). Although their primary function is to produce motion in six degrees of freedom, they also interact with the neuromuscular system to control knee motion, and hence play a vital role in knee proprioception. The majority of the muscles are monoarticular and act to primarily mobilize and secondarily stabilize the knee. Some muscles have dual actions at both the knee and hip.

\section{Type of knee arthroplasty}

Many types of prosthesis have been used for knee arthroplasty. The evolution of knee arthroplasty involves repeated cycles of failure and development for almost 40 years (Song et al., 2013). During the early stages from 1970 to 1974 , instruments of the unicondylar, duocondylar, or hinged types were used, but these were eventually abandoned due to low success rates. A total condylar type replacement was then successfully developed and became the typical model for total knee arthroplasty (TKA) (Fig.3). Recently, unicompartment knee arthroplasty (UKA) has led to good post-operative outcomes in selected patients, and arthroplasty of constrained or hinged types have been reported as useful treatments for revision surgery or combined surgery, respectively (Fig.3).

(a)

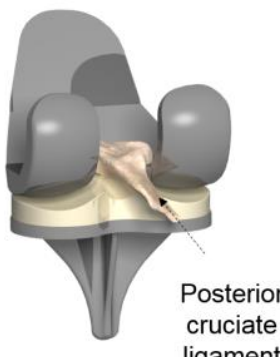

(c)

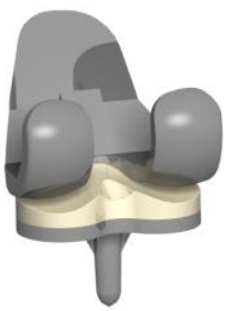

(d)

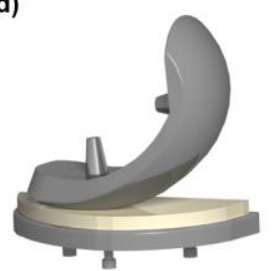

(b)

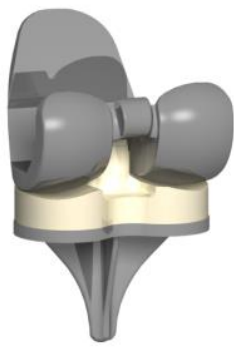

(d)

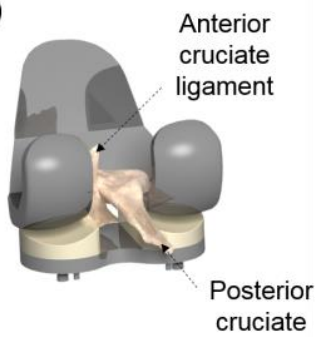

(e)

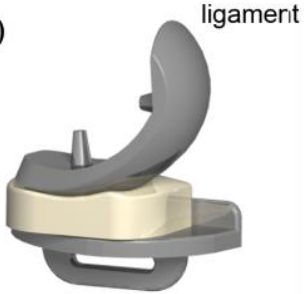

Fig. 3 Various types of TKA and UKA: (a) Fixed CR-TKA; (b) Fixed PS-TKA; (c) Mobile-bearing TKA; (d) Fixed UKA; (e) Mobile-bearing UKA

Osteoarthritis (OA) of the knee is a growing epidemic, which is affecting increasingly younger patients (Riddle et al., 2008). It usually affects the medial compartment of the TF articulation followed by the lateral compartment (Carr et al., 1993; Keyes et al., 1992). UKA has emerged in recent years as the most favored of the surgical treatments available for treating unicompartmental arthritis of the knee in elderly patients. The rate of UKA is growing three times faster than that of TKA (Riddle, Jiranek and McGlynn, 2008). Excellent and dependable clinical outcomes in the first decade of its use have encouraged surgeons to expand the indication for UKA to younger and more active patients (Vince and Cyran, 2004). The advantages of the UKA include a smaller incision, less blood loss (Jeer et al., 2005), greater range of motion (ROM) (Laurencin et al., 1991), faster recovery (Foote et al., 2010), lower perioperative morbidity (Furnes et al., 2007), preservation of normal kinematics (Patil et al., 2005) and lower overall costs (Price and Svard, 2011). Furthermore, 
conversion of a failed UKA to TKA is not as complicated as a revision TKA due to the preservation of bone stock and ligaments (Johnson et al., 2007). However, TKA is the gold standard for treating symptomatic, late-stage knee osteoarthritis OA.

Surgical techniques and implant designs have improved over the years, as evidenced by excellent survival rates and long-term results (Jones et al., 2007), but patients' satisfaction after TKA is still no more than 75\% (Noble et al., 2006; Noble et al., 2005). The demand for TKA rises as the weight of the average patient increases; moreover, a greater number of patients over 65 years old play sport and expect a better outcome than in previous years (Mont et al., 2008). Finally, the increasing demand from Asia must be considered. Design evolution in TKA must satisfy these new necessities: anatomic congruence; articolarity; less material wear and better resistance to the stresses of increased patient weight; and cost reduction.

Many types of prostheses are now widely used for TKA. However, debate still exists regarding the most appropriate prostheses for individual surgeons and particular patients. The advantages and disadvantages of each type of interposition knee arthroplasty were compared in this paper.

Removal of the ACL is required for all knee arthroplasties, but retention of the PCL depends on the type of arthroplasty. TKA designs are equally divided between PCL preservation (CR) and PCL scarifying (PS) (Fig.3). Many studies have compared the results achieved with these techniques, without a definite advantage of one over the other. Many studies prefer CR TKA (Andriacchi and Galante, 1988; Dorr et al., 1988; Ishii et al., 1998; Martelli et al., 1998), showing that retention of the PCL guarantees extensor apparatus strength, improves conservation of proprioception, improves bone stock preservation with a smaller fracture risk and allows revision surgery more easily. Other authors do not prefer one design over the other as they find similar results and characteristics (Becker et al., 1991; Bolanos et al., 1998; Dejour et al., 1999). Still, some others prefer the PS design (Freeman and Railton, 1988; Worland et al., 1997). However, the femoral resection required to make a femoral housing can become a problem for smaller knees. From a biomechanical perspective, neither PCL preservation nor substitution designs can totally replace the biomechanics of the normal knee joint (Song, Seon, Moon and Ji-Hyoun, 2013).

Traditional fixed bearing knee arthroplasties have produced good post-operative results at 10-15 years. Unfortunately, problems associated with polyethylene (PE) wear can occur in the long-term, especially in young patients. Therefore, two different fundamental design concepts are available on UKAs and TKAs: fixed-bearing and mobilebearing (MB) knee prostheses (Worland, Jessup and Johnson, 1997). MB design provides the potential advantages of a congruent bearing with lower contact stresses and polyethylene wear rates (Sathasivam et al., 2001). However, the mobile bearing provides advantages compared to fixed bearing in the short term. The long-term results in a high number of implants remain to be verified (Dall'Oca et al., 2017).

Patients may experience suboptimal functional outcomes in TKA, with a previous study reporting that $<25 \%$ of patients were satisfied with their ability to squat or kneel (Song, Seon, Moon and Ji-Hyoun, 2013). This dissatisfaction may be explained by the abnormal kinematics affecting the muscle movement arms and proprioceptive instability with removal of the ACL in TKA. The ACL contributes to the "screw-home" mechanism which is associated with anterior location of the femur on the tibia near full extension, while the PCL drives posterior femoral rollback in high flexion (Rong and Wang, 1987; Shelburne et al., 2004). In recent times, efforts to restore native knee function following TKA aim to retain both ACL and PCL

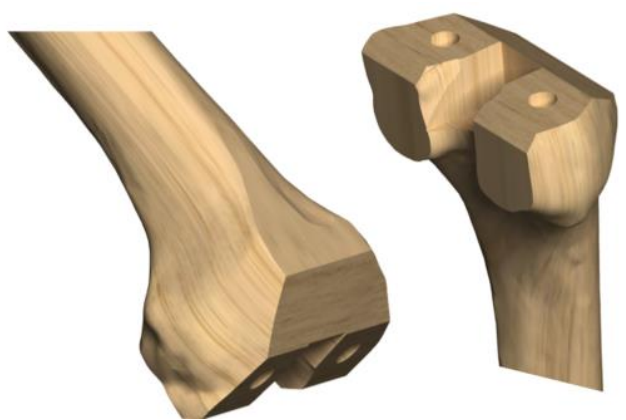

Fig. 4 Shape of a distal cut to fit a conventional femoral component.

through the use of bi-cruciate-retaining (BCR) TKA. Many studies reported that the preservation of both cruciate ligaments in TKA restores more normal knee kinematics (Banks et al., 1997; Koh et al., 2017; Moro-oka et al., 2007; 
Stiehl et al., 2000).

In a traditional knee joint arthroplasty, bones are uniformly prepared for implant component fit, resulting in a "squared-off" bone end that lacks the roundness of the natural periarticular osseous anatomy (Harrysson et al., 2007) (Fig. 4). This bone contouring can have an effect on weight distribution and can lead to the "corners" of the bone-implant interface taking on a disproportionate amount of stress, resulting in harmful bone remodeling and eventual loosening of the implant (Harrysson, Hosni and Nayfeh, 2007). There has been increased attention paid to patient-specific implants in an attempt to increase implant durability, while maintaining or decreasing associated implant costs (Schwarzkopf et al., 2015). Patient-specific implants utilize magnetic resonance imaging (MRI) or computed tomography (CT) scans to create an alignment guide for each component of the implant that is specific to a patient's unique anatomy (Schwarzkopf, Brodsky, Garcia and Gomoll, 2015). This improves implant fit and load distribution while minimizing the inefficiency and cost associated with sizing implants in the operating room (Harrysson, Hosni and Nayfeh, 2007). In addition, such an improvement in implant design through customized TKA provides normal knee kinematics and function (Zeller et al., 2017) (Fig.3)

\section{Motivation and search of computational biomechanics of knee arthroplasty}

Traditionally, there have been two reasons for performing computational modelling on knee arthroplasty: to gain a fundamental understanding of the behavior of the bone-implant system or of a specific device, and to assist with the design and pre-clinical testing of new implants in order to compare their performance with existing designs. A third application is emerging, as a decision support tool for planning of orthopedic surgery. The techniques for computerassisted surgery and customized patient instrumentation are growing and computational modelling has the potential to further improve the planning process by providing additional information about function and the potential risk of failure on a patient-by-patient basis. The main focus of this review will be knee replacement, as these have been most frequently studied, but the issues raised may be applicable to the simulation of all orthopedic devices. Studies related to the computational study of knee arthroplasty were reviewed in a meta-analysis by searching online databases (ISI Web of Knowledge, PubMed). The purpose was to identify the English-language published studies. The search was also expanded by reviewing the references of papers in order to capture all relevant data. Content experts also provided a list of relevant papers. Those irrelevant to knee arthroplasty or reported biomechanical effects irrelevant to clinical and cadaver studies were excluded.

\section{Development of computational model}

Computational models can be divided into two different types. One is a simulated model using a knee implant, and the other is modeling a subject or patient. To model a patient, medical imaging such as CT or MRI is required. Threedimensional reconstruction is then performed to develop the computational model.

Subject- or patient-specific musculoskeletal (MSK) models can be divided into multi body dynamic (MBD) and finite element (FE) models (Fig.5). Recently, many MBD software packages have been introduced to model the MSK system. The lower extremity MSK models, after experimental validation, have been used widely to simulate both joint loading and muscular actions. The majority of these dynamic models are developed based on the assumption of rigid bodies, with no deformation involved, to determine joint loading. FE models are subsequently employed to estimate the contact stresses, with detailed joint components using the load and motion profiles determined from the MBD model. Thus, an ideal computational model should combine an musculoskeletal MSK model to predict muscle forces together with a deformable contact model which also considers the implant surface geometry to predict contact mechanics (Chen et al., 2014). However, such three-dimensional multi-body knee models examined in previous studies have revealed computational challenges (Bei and Fregly, 2004). The majority of previous MSK models have assumed an idealized revolute knee joint and constrained the thigh and lower leg as a convenience in inverse dynamics analysis. The majority of reported TKA models have also neglected the influence of ligaments and muscles on contact forces and the elastic contact in joint mechanic analysis.

FE simulation can be divided into implicit and explicit analyses. Implicit FE analysis is most commonly used, however in the past decade there has been increasing application of explicit FE analyses (Fitzpatrick et al., 2011a; Fitzpatrick et al., 2010; Godest et al., 2002; Halloran et al., 2005; Knight et al., 2007). For quasistatic analyses, the 
implicit analysis is recommended; however, for dynamic analyses, problems involving large sliding contacts or very large models the explicit analysis is recommended.

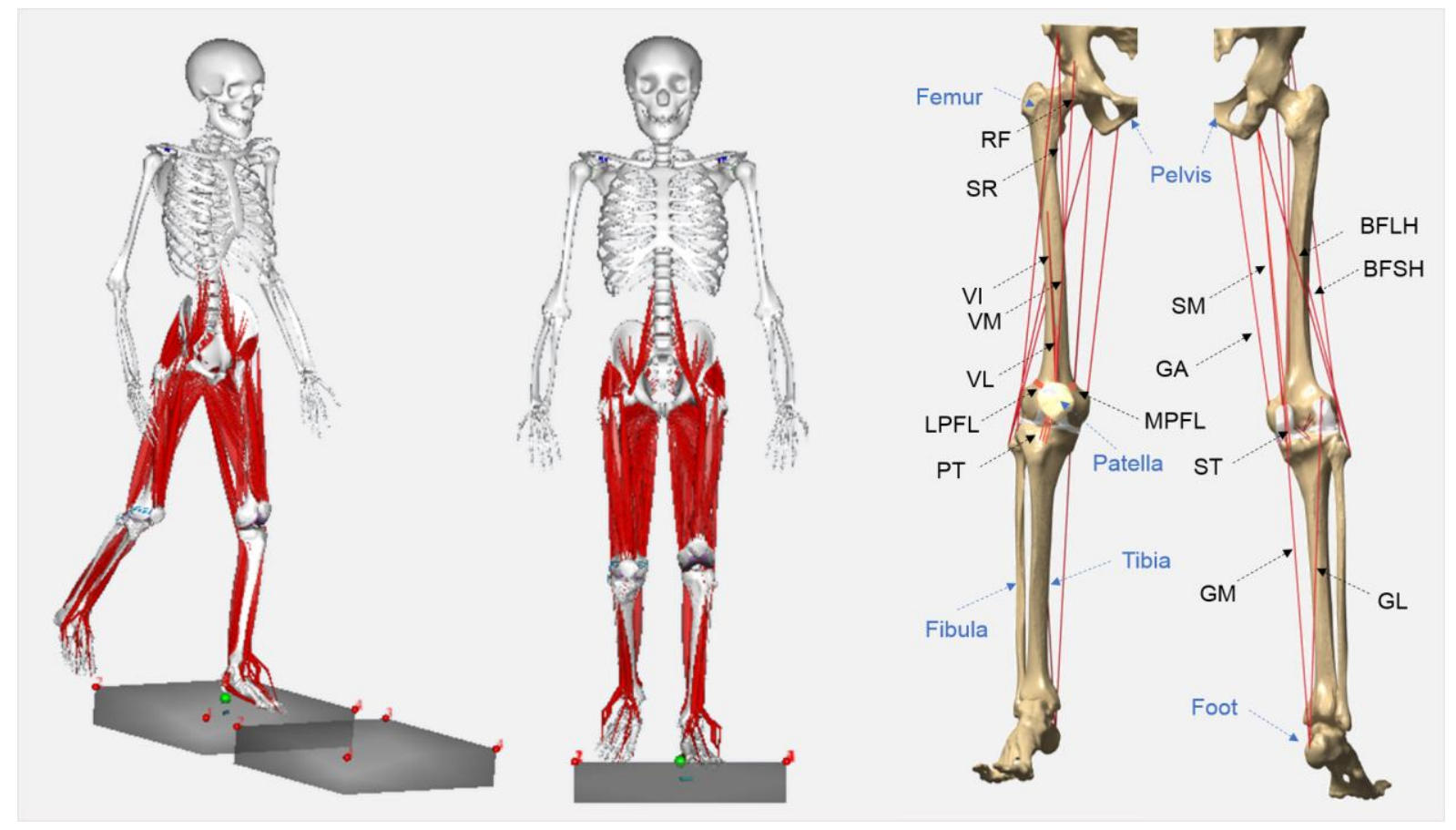

Fig. 5 Schematic of a subject-specific musculoskeletal model and finite element model

Three dimensional models developed from CT or MRI are widely used to analyze the morphology of the human body in order to obtain fundamental data for implant design. The sizes and shapes of implants also play important roles, because prostheses that match patient morphotypes provide better fixation and initial stability (Incavo et al., 1994; Westrich et al., 1995). There has been some disagreement over how the knee joints of men and women differ morphologically and whether gender-specific prostheses are required (Barrett, 2006; Conley et al., 2007; Greene, 2007). Those who contend that gender differences exist and defend the need for a female-specific prosthesis have reported morphologic differences between men and women (Hitt et al., 2003; Lingard et al., 2004; Mahfouz et al., 2007; Merchant et al., 2008). Morphological measurements have shown that female knee joints have anterior condyles that are less prominent and more diamond-shaped. Furthermore, women with the same anteroposterior (AP) length have been reported to have a narrower mediolateral (ML) width than men (Conley, Rosenberg and Crowninshield, 2007). Given these results, some have maintained that gender-specific prostheses are needed. In addition to gender differences, anatomical differences have been identified between different ethnic groups. Most prostheses have been designed to match the morphotypes of western populations, and thus Asians, who tend to have smaller morphotypes, are sometimes fitted with implants that are larger than required (Clarke and Hentz, 2008; MacDonald et al., 2008) (Fig. 6).
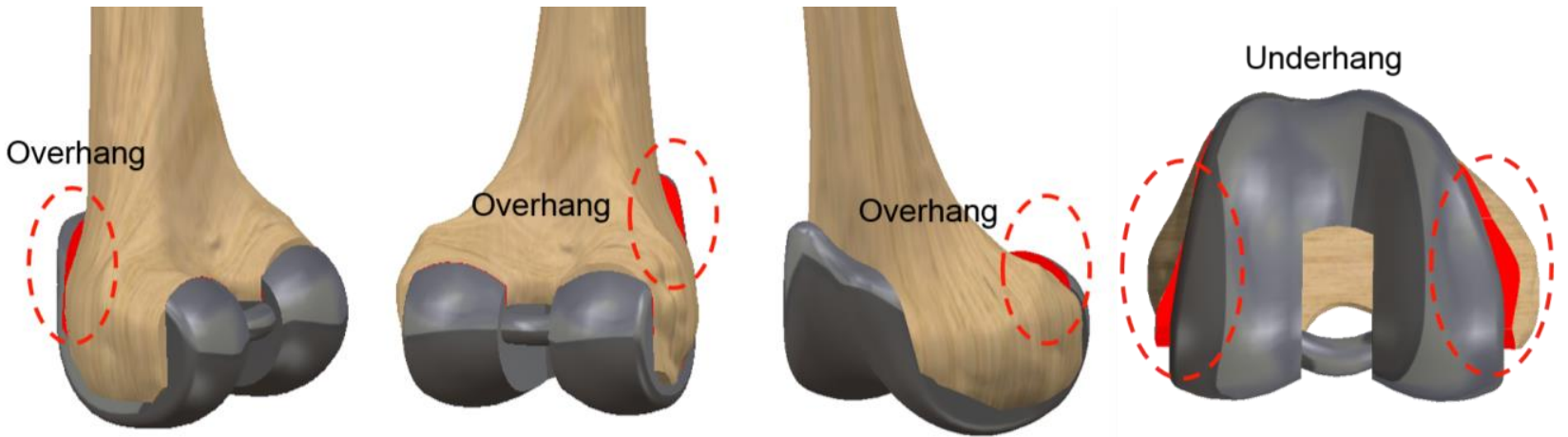

Fig. 6 Schematic of unmatched implants with the femur. 
Recently, a three-dimensional morphology study showed a gender difference for femoral posterior condylar offset and condylar height for the femoral trochlea in the Korean population (Koh et al., 2019b; Koh et al., 2019c). This study provides guidelines for the design of a suitable femoral component for TKA considering gender-specific differences in the Korean population (Koh, Nam, Chung, Kim, Chun and Kang, 2019b; Koh, Nam, Chung, Lee, Kim, Kim and Kang, 2019c).

\section{Application of computational simulation in knee arthroplasty design}

Computational simulation has been widely used in knee arthroplasty. In general, femoral component of TKA or UKA is made of cobalt chromium alloy $(\mathrm{CoCr})$, and tibial insert is made of ultrahigh-molecular-weight polyethylene (UHMWPE), and tibial component is made of titanium alloy (Ti-6Al-4V). Young's modulus $(E)$ and Poisson's ratio ( $v$ ) were as follows: $E=220 \mathrm{GPa}$ and $v=0.3(\mathrm{CoCr}) ; E=110 \mathrm{GPa}$; and $v=0.3$ (Ti-6Al-4V) (Kang et al., 2018a, Kang et al., 2019a). However, different material properties are applied depending on conventional or cross-linked in UHMWPE. The material properties are as follows: $E=463 \mathrm{MPa}$ and $v=0.46$ (Conventional); $E=673 \mathrm{MPa} v=0.46$ (Cross-linked) (Abdelgaied et al., 2014, Godest et al., 2002).

In the past, computational simulation was only used to evaluate design characteristics of implants under static conditions (Morra and Greenwald, 2003; Morra and Greenwald, 2005; Sathasivam and Walker, 1998). Such studies mainly evaluated contact stress with respect to different flexion angles, and design of the femoral component and tibial insert. This static analysis was widely used, in particular post-cam mechanism analysis in PS TKA (Huang et al., 2006; Huang et al., 2007; Watanabe et al., 2017). Watanabe et al. showed that a rounded post-cam design provided less stress concentration during flexion with rotation and at hyperextension compared with a squared design (Watanabe, Koga, Horie, Katagiri, Sekiya and Muneta, 2017). These results are useful for the development of implant designs and prediction of the contact stress on the tibial post in PS TKA (Watanabe, Koga, Horie, Katagiri, Sekiya and Muneta, 2017). Godest et al. described an explicit finite element approach to simulate both the kinematics and the internal stresses within a single analysis (Godest, Beaugonin, Haug, Taylor and Gregson, 2002). A simulation of TKA subjected to a single gait cycle within a knee wear simulator was performed and the results were compared with experimental data. They showed that an explicit finite element approach is capable of predicting the kinematics and the stresses within a single analysis at relatively low computational cost. This type of dynamic explicit FE analysis has been under development (Fitzpatrick, Baldwin, Ali, Laz and Rullkoetter, 2011a; Fitzpatrick, Baldwin and Rullkoetter, 2010; Godest, Beaugonin, Haug, Taylor and Gregson, 2002; Halloran, Petrella and Rullkoetter, 2005; Knight, Pal, Coleman, Bronson, Haider, Levine, Taylor and Rullkoetter, 2007). Ardestani et al. evaluated the underlying relationships between implant geometry as input and its performance metrics as output using dynamic simulation (Ardestani et al., 2015a). They highlighted how changes in the conformity of the femoral and tibial can impact the performance metrics. In addition, they studied combined FE simulation and principal component analysis (PCA) to evaluate the reliability and sensitivity of two PS designs versus two CR designs over a patient population (Ardestani et al., 2015b). Results showed that: (1) conformity directly affected the reliability of the knee implant over a patient population, such that lesser conformity designs had higher kinematic variability and were more influenced by AP force and IE torque; (2) contact reliability did not differ remarkably among different designs; and (3) the choice of CR or PS design affected the critical factors that influenced the reliability of each design.

Knight et al. developed this dynamic simulation further and studied an adaptive FE method capable of simulating the wear of a PE tibial insert in order to compare predicted kinematics, weight loss due to wear, and wear depth contours with results from a force-controlled experimental knee simulator (Knight, Pal, Coleman, Bronson, Haider, Levine, Taylor and Rullkoetter, 2007). Finite element-based computational wear predictions were performed to 5 million gait cycles using both force- and displacement-controlled inputs. They showed that the force-controlled inputs provided an evaluation of the overall numerical method by simultaneously predicting both kinematics and wear. Analysis of the predicted wear convergence behavior indicated that 10 iterations, each representing 500,000 gait cycles, were required to achieve numerical accuracy. Using a wear factor estimated from the literature, the predicted kinematics, polyethylene wear contours, and weight loss were in reasonable agreement with the experimental data, particularly for the stance phase of gait. Although further development of the simplified wear theory is important, the initial predictions are encouraging for future use in design phase implant evaluation.

Knight et al. used simple a simple model based on Archard's law to evaluate wear in TKA, and many others have 
begun to study this computational wear simulation. Archard introduced an equation for evaluating the linear wear depth perpendicular to the wear surface between two metal surfaces sliding relative to each other. The following equation is known as Archard's wear law:

$$
H=K w p S
$$

where $H$ is the linear wear depth, $K \mathrm{w}$ is an experimentally determined wear factor, $p$ is the contact pressure, and $S$ is the sliding distance. Netter et al. examined two design rationales for UKA: fully congruent mobile bearings, and moderately conforming fixed bearings, using experimental and computational wear simulation (Flores-Hernandez et al., 2015; Netter et al., 2015). Their study showed that increasing conformity may not be the sole predictor of wear performance, and that a highly crosslinked fixed-bearing PE insert can also provide high wear performance (Flores-Hernandez, Netter, Hermida, Steklov, Kester and D. D'Lima, 2015; Netter, Hermida, D’Alessio, Kester and D’Lima, 2015). Kang et al. evaluated the weight loss, wear depth, and kinematics for different surface properties, including nanostructured diamond (NSD), diamond-like carbon (DLC), titanium-nitride (TiN), and oxidized zirconium (OxZr), on femoral components in TKA using FE analysis under gait-cycle loading conditions (Kang et al., 2017c). Their study demonstrated the potential of OxZr and TiN for reducing PE wear and offers new insights into the effects of wear on TKA (Kang, Son, Kim, Baek, Kwon and Koh, 2017c).

TKA is a successful and durable surgical treatment (Koh et al., 2019e). During the last several decades of TKA developments, remarkable improvements have been made in implant and instrument design, and manufacturing processes (Koh, Park, Lee, Nam, Lee and Kang, 2019e). Wear of the PE tibial insert, in both fixed- and mobile-bearing TKA, is a significant factor in its long-term performance (Schroer et al., 2013). Recent reviews have shown that PE wear accounts for $10 \%$ to $18 \%$ of TKA revisions, while osteolysis accounts for less than 5\% (Dalury et al., 2013; Koh, Park, Lee, Nam, Lee and Kang, 2019e; Schroer, Berend, Lombardi, Barnes, Bolognesi, Berend, Ritter and Nunley, 2013). Computational wear models have been used to evaluate damage caused by wear and creep and subsurface damage. These models compare well to the observed PE damage (Fregly et al., 2005; Knight, Pal, Coleman, Bronson, Haider, Levine, Taylor and Rullkoetter, 2007; Zhao et al., 2008).

Numerical modeling of wear testing reduces the costs associated with in-vitro testing and the destruction of prototypes. However, only minor design optimization has been attempted for TKA design despite its great potential in this field. Optimization of the bearing surfaces of a TKR in two dimensions has been performed, considering the frontal and sagittal planes (Dargahi et al., 2003; Sathasivam and Walker, 1994). A limitation of these studies is that wear was estimated only based on contact pressure, while recent work has shown that the contact pressure can be increased with reduced wear rates (Essner et al., 2003). As well, the two-dimensional simplifications of these models required that no axial rotation or torque could be applied. Willing and Kim performed shape optimization of the articular surfaces of the TF joint of a right-leg TKA using a three-dimensional FE model. Their wear model takes sliding distance, contact area and contact pressure into account, as well as three-dimensional transient loading based on wear testing standards (Willing and Kim, 2008). In addition, they performed multiobjective design optimization (MOO) using the adaptive weighted sum (AWS) method in order to determine a set of pareto-optimal implant designs while simultaneously considering durability and kinematics (Willing and Kim, 2012). They found that the competing relationship between durability and kinematics was confirmed and quantified using optimization methods (Willing and Kim, 2012).

As previously mentioned, the aspects of knee arthroplasty of most interest are to preserve natural knee kinematics and to expand the life span of the implant. Interest in patient-specific TKA has therefore been increasing. Dynamic simulation methods can also be used in the design of patient-specific TKA. Koh et al. investigated the biomechanical effect of three different TKA designs with respect to TF conformity in customized PS-TKAs (Koh et al., 2019f). The articular geometry for the curvature of a tibial insert is derived from the femoral component in current patient-specific TKA (Wang et al., 2018; White and Ranawat, 2016; Zeller, Sharma, Kurtz, Anderle and Komistek, 2017). However, Koh et al.'s study indicated that changes in the TF articular surface conformity led to changes in contact mechanics, as well as kinematic changes during a gait cycle. In addition, the change in conformity affected the post-cam engagement (Koh, Son, Kwon, Kwon and Kang, 2019f). A tibial insert with an anatomical mimetic design did not exhibit the best wear performance; however, an improvement in performance can be attained through optimization of the anatomical mimetic design PSTKA TF articular surface conformity. The articular surface conformity should therefore be carefully selected for a customized PS-TKA because it may affect the post-cam mechanism as well as wear performance (Koh, Son, Kwon, 
Kwon and Kang, 2019f). Koh et al. recently evaluated wear prediction with respect to TF conformity design in patientspecific UKA under gait loading conditions by using a previously validated computational wear method (Koh et al., 2019d). Their results indicated that increased conformity provided improvements in wear but resulted in limited kinematics. Increased conformity should thus be avoided in fixed-bearing patient-specific UKA design. A flat or plateau anatomy mimetic tibial insert design was recommended in patient-specific UKA (Koh, Park, Lee and Kang, 2019d).

The fundamental building block of any computational analysis is the model of the intact or implanted bone segment or joint, including the assigned material properties and associated loading and boundary conditions. Assumptions made at this level have consequences on the subsequent results, regardless of the complexity of the simulation. Since its first use in the 1970s (Brekelmans et al., 1972). There has been remarkable improvement in the fidelity of FE models; however, it is important to understand the state-of-the-art models and the limitations of current simulations (Taylor and Prendergast, 2015). In terms of model geometry and mesh, we have moved from idealized two-dimensional models to anatomical subject-specific three-dimensional models, the latter now being used in the majority of cases (Vasu et al., 1982; Vasu et al., 1986). Subject- or patient-specific modeling of the human body has had challenging problems in terms of validation. If a subject- or patient-specific model was developed based on cadaveric data, it could be validated using its in vitro results (Baldwin et al., 2009; Baldwin et al., 2012; Fitzpatrick et al., 2011c). If it was not based on a cadaver, there are limitations in validation. For the initial computational model, it was assumed to be validated if a representative model lay within the range of standard deviation in in-vitro cadaver experimental results (Kang et al., 2017b). Recently, as subject- or patient-specific models are developed, they are validated by comparison with electromyography (EMG) signals and muscle activity in musculoskeletal MBD, and medical imaging in FE models (Kang et al., 2017a; Kang et al., 2015; Kang et al., 2017d; Kang et al., 2017e). The dynamic multibody rigid models are limited to the evaluation of stress distribution in the knee joint. By contrast, deformable body FE models enable evaluation of the ligament forces and contact stresses on the TF and PF joints, which are important for understanding the factors that may affect structural joint deterioration (Akbarshahi et al., 2014; Carter et al., 2004). The available data on muscle forces in FE models are not subject-specific, but they have been obtained from previous studies (Adouni and Shirazi-Adl, 2014; Kiapour et al., 2014)

Studies using a validated FE model that includes all major ligaments and soft tissues for comparing subject-specific muscle forces have seldom been reported. Recently, Kang et al. have introduced and validated a 12-degree of freedom (DOF) (TF, 6 DOF; and PF, 6 DOF) MSK model of the knee suitable for force-dependent kinematic simulation under gait and squat loading conditions, followed by validation using EMG sensors and muscle-force activation (Kang, Koh, Son, Kim, Choi, Jung and Kim, 2017a). MSK models to apply the appropriate muscle force corresponding to the subject's FE model were then used for validation. Fitzpatrick et al. showed the effect of implant design on engagement dynamics of the post-cam mechanism and resulting polyethylene stresses during dynamic activity using subject specific models (Fitzpatrick et al., 2013). Their results showed that condylar geometry, in addition to post-cam geometry, played a significant role in minimizing engagement velocity and forces and stresses in the post (Fitzpatrick, Clary, Cyr, Maletsky and Rullkoetter, 2013). Koh et al. investigated the preservation of normal knee biomechanics by using specific articular surface conformity in customized PS and CR-TKA (Koh et al., 2019a; Koh et al., 2018a; Koh et al., 2018b; Koh et al., 2018c). In addition, Kang et al. compared the biomechanical effect between patient specific and standard off-the-shelf prostheses for UKA (Kang et al., 2018k). Their results showed that patient-specific UKA provided mechanics close to those of the normal knee joint. The decreased contact stress on the opposite compartment may reduce the overall risk of progressive osteoarthritis (Kang, Son, Suh, Kwon, Kwon and Koh, 2018k). Studies on biomimetic TKA were also conducted using an MBD model (Varadarajan et al., 2015a; Varadarajan et al., 2015b; Zumbrunn et al., 2018; Zumbrunn et al., 2015). These studies demonstrated that the biomimetic-CR showed medial pivot motion, while other CR implants showed abnormal motion including lateral or no pivot, and paradoxical anterior sliding during deep knee bend and chairsitting (Varadarajan, Zumbrunn, Rubash, Malchau, Li and Muratoglu, 2015a). In addition, restoring native knee geometry with ACL preservation provided kinematic improvements over contemporary ACL-preserving and ACL-sacrificing implants (Zumbrunn, Varadarajan, Rubash, Malchau, Li and Muratoglu, 2015). In other words, many studies stated that prosthetic design with native knee anatomy is required to preserve native knee kinematics (Kang, Son, Suh, Kwon, Kwon and Koh, 2018k; Koh, Lee, Chung and Kang, 2019a; Koh, Nam and Kang, 2018a; Koh, Son, Kwon, Kwon and Kang, 2018b; Koh, Son, Kwon, Kwon and Kang, 2018c; Varadarajan, Zumbrunn, Rubash, Malchau, Li and Muratoglu, 2015a; Varadarajan, Zumbrunn, Rubash, Malchau, Muratoglu and Li, 2015b; Zumbrunn, Duffy, Rubash, Malchau, Muratoglu and Varadarajan, 2018; Zumbrunn, Varadarajan, Rubash, Malchau, Li and Muratoglu, 2015). ACL-substituting implants could be an effective surgical treatment capable of overcoming the limitations of contemporary TKA, especially in cases 
where retaining the native ACL is not feasible or is challenging.

\section{Application of computational simulation in pre- or post-clinical evaluation}

Computational simulation used for pre- or post-clinical evaluation must be based on bony structure and soft tissue models. To evaluate bone, it can be modeled with actual material properties or with rigid body properties if there is no interest in the bone itself. In this paper, computational simulation for clinical evaluation of UKA and TKA is examined.

For UKA, all tibial, bone and implants were modeled for clinical evaluation in initial studies (Iesaka et al., 2002; Inoue et al., 2016; Pegg et al., 2013; Simpson et al., 2009). After unicompartmental knee replacement, the most common site for pain is antero-medial over the proximal tibia. The reason for this is not clear; however, it may be due to high bone strain (Simpson, Price, Gulati, Murray and Gill, 2009). Previous studies have demonstrated that there was a significant increase in strain, antero-medially on the proximal tibia, following implantation with a unicompartmental knee replacement. This may be the cause of antero-medial pain. As the bone remodels over time this strain decreases, which explains why the pain usually settles within 12 months after surgery. However, errors in implantation can result in strain values that may lead to degenerative remodeling and/or increased micro-damage of the bone. This may explain why the pain progressively worsens in some cases (Simpson, Price, Gulati, Murray and Gill, 2009). In addition, Inoue et al. investigated the effects of the tibial inclination in the coronal plane on stresses developed in the proximal tibial condyle, using the FE model with or without extended sagittal bone cuts of the posterior tibial cortex (Inoue, Akagi, Asada, Mori, Zaima and Hashida, 2016). Their study showed that the risk of medial tibial condylar fractures increases with increasing valgus inclination of the tibial component and with increased extension of the sagittal cut in the posterior tibial cortex (Inoue, Akagi, Asada, Mori, Zaima and Hashida, 2016). However, recent studies have focused not only on stress or strain on bone, but also looked at stress on soft tissue. Therefore, modeling not only of the femur, but also of cartilage and the lateral meniscus became required (Innocenti et al., 2014; Innocenti et al., 2016; Kang et al., 2018f; Kang et al., 2019c; Kang et al., 2018h; Kang et al., 2018i; Kang et al., 2018j; Kwon et al., 2014; Kwon et al., 2017; Park et al., 2019; Simpson, Price, Gulati, Murray and Gill, 2009; Wen et al., 2017; Zhu et al., 2015).

These simulations can be divided into two types, static and dynamic. Innocenti el al. showed that even if a medial UKA was well aligned with normal soft tissue tension and with correct thickness of the tibia component, it induced a stiffness modification in the joint that altered the load distribution between the medial and lateral compartments. The bone stress and ligament strain can potentially lead to an osteoarthritic progression under static loading conditions (Innocenti, Bilgen, Labey, van Lenthe, Sloten and Catani, 2014). In addition, Kang et al. showed that the best position for the femoral component in UKA could be the center of the distal femoral condyle under dynamic loading conditions (Kang, Son, Koh, Kwon, Kwon, Lee and Park, 2018i). Femoral component position could be one of the important factors that influence the contact stresses on the tibial insert and articular cartilage, hence the postoperative significance of the femoral component position in UKA (Kang, Son, Koh, Kwon, Kwon, Lee and Park, 2018i).

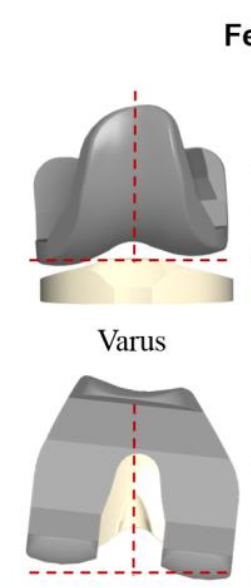

Internal

\section{Femoral Component}

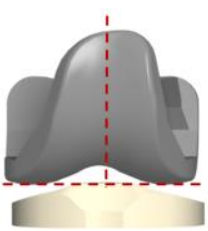

Neutral

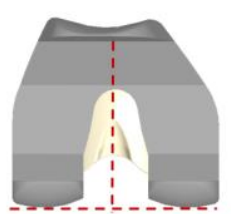

Neutral

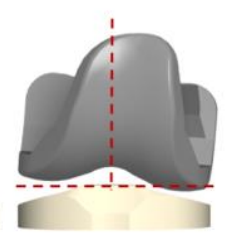

Valgus

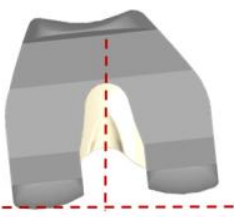

External

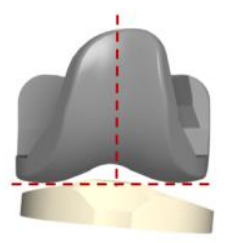

Varus

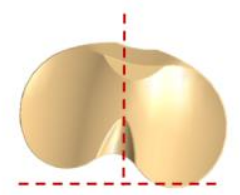

Internal

\section{Tibial Insert}

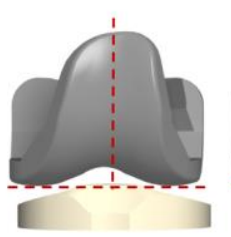

Neutral

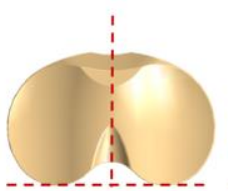

Neutral

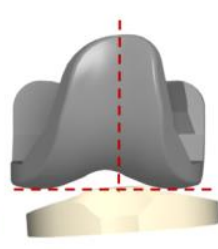

Valgus

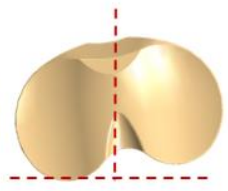

External

Fig. 7 Schematic of the varying configurations for the misalignment of components in left TKA. 
For TKA, as with UKA, there are two different methods of modeling; with the bone having appropriate material properties or regarding it as a rigid body. Modeling with the bone having material properties has often been performed in studies related to the tibia (Au et al., 2007; Kim et al., 2008; Perillo-Marcone and Taylor, 2007). Au et al. evaluated the effects of material properties and three characteristics of loading conditions on the bone stress state for a prosthesis similar to a commercially available model (Au, James Raso, Liggins and Amirfazli, 2007). Their results showed that restoration of preoperative stress levels in the tibia and reduction of bone resorption requires careful consideration of the effects of loading conditions such as load placement on the condylar surface, contact patterns, and bone or implant condylar surface geometry. Material properties such as a stiff implant can also be beneficial in more distal regions of bone in the design of TKA (Au, James Raso, Liggins and Amirfazli, 2007).

Many studies on misalignment of components have also used a rigid body bone model (Fig. 7). Such studies have been performed in both FE and MBD models (Essner et al., 2011; Kang et al., 2018a; Kang et al., 2016; Kang et al., 2017f; Kang et al., 2018b; Kang et al., 2018c; Kang et al., 2018e; Kang et al., 2019b; Kang et al., 2018g; Kuriyama et al., 2014; Marra et al., 2018; Suh et al., 2017; Thompson et al., 2011). Investigations have included pre- or post-clinical evaluation for translation and rotation in coronal and sagittal planes.

Internal-external misalignment of the femoral component was widely studied using MBD and FE models (Thompson, Hast, Granger, Piazza and Siston, 2011). Thompson et al. found that femoral rotation had a greater effect on quadriceps forces, collateral ligament forces, and varus/valgus kinematics, while tibial rotation affected anteroposterior translations (Thompson, Hast, Granger, Piazza and Siston, 2011). Kang et al. found that forces on the MCL and the LCL increased in internal and external femoral malrotations, respectively (Kang, Koh, Son, Kwon, Baek, Jung and Park, 2016)

Many studies related to the biomechanical effect were performed in terms of anterior-posterior misalignment in femoral component (Kang, Koh, Son, Kwon, Lee and Kwon, 2017f; Kang, Koh, Son, Kwon, Lee and Kwon, 2018c; Kang, Kwon, Kwon, Lee and Koh, 2019b; Kang, Kwon, Son, Kwon, Lee and Koh, 2018g). Kang et al. found that contact stress on the patellar button increased and decreased as posterior condylar offset moved between the anterior and posterior directions, respectively. Higher quadriceps muscle and patellar tendon force are required as the posterior condylar offset moved in the anterior direction with an equivalent flexion angle. The forces exerted on the PCL increased as posterior condylar offset moved in the posterior direction (Kang, Koh, Son, Kwon, Lee and Kwon, 2018c). They found that change in posterior condylar offset alternatively provided positive and negative biomechanical effects. They also found that posterior condylar offset magnitude was influenced by a postoperative change in the kinematics in CR-TKA, although a relatively smaller effect was observed in PS-TKA (Kang, Kwon, Kwon, Lee and Koh, 2019b). Surgeons should therefore take care in changing the posterior condylar offset, especially for CR-TKA (Kang, Kwon, Kwon, Lee and Koh, 2019b). Kang et al. also determined the extent of the impact of the femoral component's sagittal alignment on kinematics and biomechanics in terms of the sagittal plane of the femoral component (Kang, Koh, Son, Kwon and Park, 2018e). They found that the femoral component sagittal position is an important factor in knee joint mechanics. The flexion of the femoral component showed a stable reconstruction of the knee extensors' mechanism. Surgeons may consider a neutralto-mild flexed femoral component position, without concerns of anterior notching of the femoral cortex.

Many studies have also examined misalignment of the tibial component (Kang, Kwon, Son, Kwon, Lee and Koh, 2018a; Kang et al., 2018d; Kang, Kwon, Son, Kwon, Lee and Koh, 2018g; Kuriyama, Ishikawa, Furu, Ito and Matsuda, 2014; Suh, Kang, Son, Kwon, Baek and Koh, 2017). Kuriyama et al. evaluated traction forces in the LCL and MCL with a malrotated tibial component during squatting using computational simulation (Kuriyama, Ishikawa, Furu, Ito and Matsuda, 2014). They also evaluated TF and PF contact forces and stresses under similar conditions. They found that with internal rotation of the tibial component, the MCL force increased progressively; the LCL force also increased, but only up to less than half of the MCL force values (Kuriyama, Ishikawa, Furu, Ito and Matsuda, 2014). A higher degree of constraint of the tibial component was associated with greater femoral rotational movement and higher MCL forces (Kuriyama, Ishikawa, Furu, Ito and Matsuda, 2014). The tibiofemoral and patellofemoral contact forces were not influenced by malrotation of the tibial component, but the contact stresses increased because of decreased contact area (Kuriyama, Ishikawa, Furu, Ito and Matsuda, 2014). In addition, there have been studies on misalignment of the tibial component in the sagittal plane (Kang, Kwon, Son, Kwon, Lee and Koh, 2018a; Kang, Koh, Son, Kwon, Lee and Kwon, 2018b; Kang, Koh, Son, Kwon, Lee and Kwon, 2018d; Kuriyama, Ishikawa, Furu, Ito and Matsuda, 2014). Kang et al. investigated the effect of the posterior tibial slope (PTS) on TF kinematics, PF contact stress, and forces on the quadriceps, PCL and collateral ligament after cruciate-retaining TKA using computer simulations (Kang, Koh, Son, Kwon, Lee and Kwon, 2018d). They found that the PTS increased medial and lateral movements without paradoxical motion. However, 
an excessive PTS indicated progressive loosening of the TF joint gap due to a reduction in collateral ligament tension during flexion. They also discovered that tibial posterior translation and external rotation increased as the PTS increased in both CR and PS-TKAs. There was no remarkable difference in external rotation between CR and PS-TKAs. However, for the mobile-bearing TKA, PTS had less effect on the kinematics. Based on their computational simulation, PTS is the critical factor that influences kinematics in TKA, particularly in the CR-TKA. The surgeon should therefore take care in choosing the PTS in CR-TKAs. Marra et al. investigated the effect of tibial slope on knee laxity, kinematics and forces in squatting activity using computer simulation (Marra, Strzelczak, Heesterbeek, van de Groes, Janssen, Koopman, Wymenga and Verdonschot, 2018). They hypothesized that the effects depend on the referencing technique. They found that changes in posterior tibial slope have effects on knee laxity, kinematics and forces. A greater posterior tibial slope with the anterior tibial cortex technique increases the knee laxity in flexion, but also, unexpectedly, in extension. A greater posterior slope with the center of tibial plateau technique leaves the knee laxity almost uninfluenced, is beneficial for the knee extensor apparatus and relieves the pressure on the PF joint. The tibial resection should therefore be preplanned and executed as accurately as possible using the center of tibial plateau technique.

Computational studies have been performed in the field on aspects other than misalignment of components (Fitzpatrick et al., 2016; Kang et al., 2019a; Nakamura et al., 2017). Nakamura et al. investigated the kinematics, contact forces and stress, and bone strain in kinematically aligned (KA) and mechanically aligned (MA) TKA using computational simulation (Nakamura, Tian, Tanaka, Kuriyama, Ito, Furu and Matsuda, 2017). They found near-normal kinematics in KA-TKA. However, KA-TKA increased the contact force, stress and bone strain on the medial side for moderate and severe varus knee models. The application of KA-TKA for severe varus knees could be inappropriate (Nakamura, Tian, Tanaka, Kuriyama, Ito, Furu and Matsuda, 2017). Fitzpatrick et al. examined whether a surrogate model allows micromotion prediction over the entire bone-implant interface and evaluated the effectiveness of a leaveone-out (LOO) approach (Fitzpatrick et al., 2014). They showed that surrogate models have significant potential to rapidly predict micromotion over the entire bone-implant interface, allowing greater range in loading conditions to be explored than is possible through conventional methods. Berahmani et al. also studied how these simplifications affect micromotions at the bone-implant interface of an uncemented femoral component (Berahmani et al., 2016). They suggested that a simplified peak force can be used to assess the stability of cementless femoral components. Abo-Alhol et al. looked at the effect of component design based on PF mechanics during a kneeling activity (Abo-Alhol et al., 2014). They showed that the anatomic patella design demonstrated increased strains inferiorly, while the dome and medialized dome showed increases centrally. An understanding of the effect of implant design on patellar mechanics during kneeling may provide guidance to component designs that reduces knee pain and patellar fracture during kneeling (Fitzpatrick, Hemelaar and Taylor, 2014). Such computational studies provide guidelines for possible pre- and post-operative problems that may occur in orthopedic surgery.

\section{Discussion \& Conclusions}

In this review paper we have summarized how computational biomechanics are used in knee arthroplasty design and pre- or post-clinical evaluation. Engineers who design implants have a range of sophisticated modelling tools capable of replicating a variety of mechanical and biological processes in order to assess the mechanical behavior and performance of orthopedic devices.

Computational study improves knee arthroplasty through preclinical design optimization and by advancing insight into the knee biomechanics (Rullkoetter et al., 2017). Validated models can be used to evaluate many design variabilities without manufacturing physical prototypes (Rullkoetter, Fitzpatrick and Clary, 2017). The designer identifies the primary features of a new implant, using the computing design parameters until an optimal combination is reached. Models also provide insight into measures not easily obtained experimentally, such as contact mechanics, interface shear loading, or muscle force requirements during a dynamic activity (Rullkoetter, Fitzpatrick and Clary, 2017). Previous work has shown the role of computational analysis in deciphering the complex interplay between component positioning of the implanted TKA and the kinetics of soft-tissue structures (Clement and Deehan, 2018).

However, our current ability to apply these techniques to their full potential is limited until some challenges are overcome. The development of subject-specific computational models and their application are well established in the literature. Modelling approaches are now available that are subject-specific and have the potential to account for intersubject variability, ranging from a single bone or joint through to population-based modelling. As with all computational 
studies, the type of analysis and approach used will be dependent on the question being asked. A single representative subject-specific model can have advantages. They can be used to sweep through multiple design parameters in order to provide a relative ranking of performance. They are suitable for detecting large differences in performance, which are likely to occur independently of bone morphology or properties. The limitation of a single subject-specific model is the inability to consider variations of morphology and bone properties when evaluating designs. Caution should be exercised in placing too much significance on slight differences predicted using a single model, because these may well be lost or become insignificant when anatomical variation is included. When attempting to differentiate differences between implant designs or robustness, there is a need to account for patient variation in terms of morphology, bone properties and loading and boundary conditions.

Modelling of small groups in terms of bone segments or joints has been shown to be useful in comparing the performance of surgical variability (Huang, Liau, Huang and Cheng, 2006; Watanabe, Koga, Horie, Katagiri, Sekiya and Muneta, 2017), and this has certainly become easier in the preprocessing software. These studies have the advantage that they begin to evaluate the influence of bone morphology, and variation in bone properties and the applied loading/boundary conditions. Because there are multiple samples, it is possible to perform statistical analysis to investigate whether observed differences are significant. There are limitations, however; it is difficult to assess effectively whether the changes in geometry across an implant size range potentially have an impact on performance, because there may not be sufficient samples for each implant size to have meaningful statistical power. When considering the time needed to perform simulations, the model generation process can be a significant proportion of the overall simulation process. We should, therefore, aim to exploit each generated model. In addition, the usefulness of these studies could be further extended by parametrically or probabilistically varying the bone properties and loading/boundary conditions.

The major advance in computational model has been the improvements in study design through the implementation of statistical methods, especially for probabilistic analyses (Laz and Browne, 2010). There are challenges in developing and implementing them particularly if patient variability and implant positioning are considered. However, simpler studies can be performed which can yield useful information about the behavior of the bone-implant. Computational modelling is often found as a quick and easy alternative to in vitro testing, but in reality, there is usually significant time needed to develop a model. If this model is then used only once, it is not being used to its full potential.

To account for patient variability, the application of statistical shape and intensity models are being developed (Fitzpatrick et al., 2011b; Smoger et al., 2015; Smoger et al., 2017; Taylor et al., 2013). These models have the potential to generate thousands of representative models based on a much smaller training data set. Combined with the automatic prosthetic implantation process, statistical shape and intensity models provides powerful technique for assessing the next generation of implant designs and pre- or post-clinical evaluation (Taylor, Bryan and Galloway, 2013).

Modeling of knee arthroplasty has progressed significantly over the last decade. A model is available to evaluate implant stability and mobility characteristics, enabling rapid evaluation of design concepts. Primary limitations currently include an oversimplified passive soft-tissue representation and a lack of data from the post-operative balance condition. The increased use of intraoperative sensors may provide supporting in vivo data and establish balancing targets (D'Lima and Colwell, 2017). These models should facilitate an improved understanding of the relative contribution to stability from passive constraint, implant design and alignment, and joint loading. Modeling will also be focused on an understanding of the relationship between joint mechanics and patient function and satisfaction (Banks, 2017). This only occurs through holistic collaborative studies including clinical data, patient measurement, modeling, and retrieval analysis. As implants are available that were created using preclinical computational prediction, it is now possible to close the loop with clinical data in order to evaluate the quality and predictive power of the models used.

In the future, computational analysis will play a more important role in understanding the behavior of knee arthroplasty. Through improved study design and close corroboration with in vitro testing, we rely on simulations in the development and pre-clinical testing of devices. There are challenges to the use of computational models as part of a decision process for planning orthopedic surgery, but advances in model generation techniques and solution methodologies may lead to the increased use of this technology in future. This paper presents current modeling capabilities for implant design and stability, with further suggestions for how an implant might perform throughout the population. However, simulations must include closely corroborated multi-domain analysis that account for real-life variability.

\section{Acknowledgement}


Kyoung-Tak Kang and Yong-Gon Koh contributed equally to this work and should be considered co-first authors.

\section{Abbreviations}

The following abbreviations are used in this manuscript.

ACL: Anterior cruciate ligament; AP: Anteroposterior; BCR: Bi-cruciate-retaining; BFLH: Biceps femoris long head; BFSH: Biceps femoris short head; CR: PCL preservation; CoCr: Cobalt Chromium Alloy; CT: Computed tomography; DLC: Diamond-like carbon; EMG: Electromyography; GA: Gracilis; GM: Gastrocnemius medial; GL: Gastrocnemius lateral; KA: Kinematically aligned; LCL: Lateral collateral ligament; LPFL: Lateral patello femoral ligament; MA: Mechanically aligned; MBD: Multi body dynamic; MCL: Medial collateral ligament; ML: Mediolateral; MPFL: Medial patellofemoral ligament; MRI: Magnetic resonance imaging; MSK: Musculoskeletal; NSD: Nanostructured diamond; OA: Osteoarthritis; OxZr: Oxidized zirconium; PCA: Principal component analysis; PCL: Posterior cruciate ligament; PE: Polyethlene; PF: Patellofemoral; PS: PCL scarifying; PT: Patellar tendon; PTS: Posterior tibial slope; RF: Rectus femoris; ROM: Range of motion; SM: Semimembranous; ST: Semitendinosus; SR: Sartorius; TF: Tibiofemoral; Tin: Titaniumnitride; Ti-6Al-4V: titanium alloy; TKA: Total knee arthroplsty; VI: Vastus intermidus; VL: Vastus lateralis; VM: Vastus medialis; UHMWPE: Ultrahigh-Molecular-Weight Polyethylene; UKA: Unicompartment knee arthroplasty.

\section{References}

Abdelgaied, A., Brockett, C.L., Liu, F.; Jennings, L.M., Jin, Z. and Fisher, J, The effect of insert conformity and material on total knee replacement wear, Journal of Proceedings of the Institution of Mechanical Engineers, Vol. 228, No. 1 (2014), pp. 98-106.

Abo-Alhol, T. R., Fitzpatrick, C. K., Clary, C. W., Cyr, A. J., Maletsky, L. P., Laz, P. J. and Rullkoetter, P. J., Patellar mechanics during simulated kneeling in the natural and implanted knee, Journal of biomechanics, Vol. 47, No. 5 (2014), pp. 1045-1051, DOI: 10.1016/j.jbiomech.2013.12.040.

Abulhasan, J. F. and Grey, M. J., Anatomy and Physiology of Knee Stability, Journal of Functional Morphology and Kinesiology, Vol. 2, No. 4 (2017), DOI: 10.3390/jfmk2040034

Adouni, M. and Shirazi-Adl, A., Evaluation of knee joint muscle forces and tissue stresses-strains during gait in severe OA versus normal subjects, Journal of Orthopaedic Research Vol. 32, No. 1 (2014), pp. 69-78, DOI: $10.1002 /$ jor.22472.

Akbarshahi, M., Fernandez, J. W., Schache, A. G. and Pandy, M. G., Subject-specific evaluation of patellofemoral joint biomechanics during functional activity, Medical engineering \& physics, Vol. 36, No. 9 (2014), pp. 1122-1133, DOI: 10.1016/j.medengphy.2014.06.009.

Andriacchi, T. P. and Galante, J. O., Retention of the posterior cruciate in total knee arthroplasty, The Journal of arthroplasty, Vol. 3 Suppl, (1988), pp. S13-19.

Ardestani, M. M., Moazen, M. and Jin, Z., Contribution of geometric design parameters to knee implant performance: Conflicting impact of conformity on kinematics and contact mechanics, The Knee, Vol. 22, No. 3 (2015a), pp. $217-$ 224, DOI: 10.1016/j.knee.2015.02.011.

Ardestani, M. M., Moazen, M., Maniei, E. and Jin, Z., Posterior stabilized versus cruciate retaining total knee arthroplasty designs: conformity affects the performance reliability of the design over the patient population, Medical engineering \& physics, Vol. 37, No. 4 (2015b), pp. 350-360, DOI: 10.1016/j.medengphy.2015.01.008.

Au, A. G., James Raso, V., Liggins, A. B. and Amirfazli, A., Contribution of loading conditions and material properties to stress shielding near the tibial component of total knee replacements, Journal of biomechanics, Vol. 40, No. 6 (2007), pp. 1410-1416, DOI: 10.1016/j.jbiomech.2006.05.020.

Baldwin, M. A., Clary, C., Maletsky, L. P. and Rullkoetter, P. J., Verification of predicted specimen-specific natural and implanted patellofemoral kinematics during simulated deep knee bend, Journal of biomechanics, Vol. 42, No. 14 (2009), pp. 2341-2348, DOI: 10.1016/j.jbiomech.2009.06.028.

Baldwin, M. A., Clary, C. W., Fitzpatrick, C. K., Deacy, J. S., Maletsky, L. P. and Rullkoetter, P. J., Dynamic finite element knee simulation for evaluation of knee replacement mechanics, Journal of biomechanics, Vol. 45, No. 3 (2012), pp. 474-483, DOI: 10.1016/j.jbiomech.2011.11.052. 
Banks, S. A., What Postoperative Outcome Measures Link Joint Stability to Patient Satisfaction?, Journal of the American Academy of Orthopaedic Surgeons, Vol. 25 Suppl 1, (2017), pp. S40-S43, DOI: 10.5435/jaaos-d-16-00628.

Banks, S. A., Markovich, G. D. and Hodge, W. A., In vivo kinematics of cruciate-retaining and -substituting knee arthroplasties, The Journal of arthroplasty, Vol. 12, No. 3 (1997), pp. 297-304.

Barrett, W. P., The need for gender-specific prostheses in TKA: does size make a difference?, Orthopedics, Vol. 29 , No. 9 Suppl (2006), pp. S53-55.

Becker, M. W., Insall, J. N. and Faris, P. M., Bilateral total knee arthroplasty. One cruciate retaining and one cruciate substituting, Clinical orthopaedics and related research, No. 271 (1991), pp. 122-124.

Bei, Y. and Fregly, B. J., Multibody dynamic simulation of knee contact mechanics, Medical engineering \& physics, Vol. 26, No. 9 (2004), pp. 777-789, DOI: 10.1016/j.medengphy.2004.07.004.

Berahmani, S., Janssen, D., Wolfson, D., de Waal Malefijt, M., Fitzpatrick, C. K., Rullkoetter, P. J. and Verdonschot, N., $\mathrm{FE}$ analysis of the effects of simplifications in experimental testing on micromotions of uncemented femoral knee implants, Journal of Orthopaedic Research Vol. 34, No. 5 (2016), pp. 812-819, DOI: 10.1002/jor.23074.

Bolanos, A. A., Colizza, W. A., McCann, P. D., Gotlin, R. S., Wootten, M. E., Kahn, B. A. and Insall, J. N., A comparison of isokinetic strength testing and gait analysis in patients with posterior cruciate-retaining and substituting knee arthroplasties, The Journal of arthroplasty, Vol. 13, No. 8 (1998), pp. 906-915.

Brekelmans, W. A., Poort, H. W. and Slooff, T. J., A new method to analyse the mechanical behaviour of skeletal parts, Acta orthopaedica Scandinavica, Vol. 43, No. 5 (1972), pp. 301-317.

Buckwalter, J. A., Articular cartilage injuries, Clinical orthopaedics and related research, No. 402 (2002), pp. 21 -37.

Carr, A., Keyes, G., Miller, R., O'Connor, J. and Goodfellow, J., Medial unicompartmental arthroplasty. A survival study of the Oxford meniscal knee, Clinical orthopaedics and related research, No. 295 (1993), pp. 205-213.

Carter, D. R., Beaupre, G. S., Wong, M., Smith, R. L., Andriacchi, T. P. and Schurman, D. J., The mechanobiology of articular cartilage development and degeneration, Clinical orthopaedics and related research, No. 427 Suppl (2004), pp. S69-77.

Chen, Z., Zhang, X., Ardestani, M. M., Wang, L., Liu, Y., Lian, Q., He, J., Li, D. and Jin, Z., Prediction of in vivo joint mechanics of an artificial knee implant using rigid multi-body dynamics with elastic contacts, Proceedings of the Institution of Mechanical Engineers, Part H: Journal of Engineering in Medicine, Vol. 228, No. 6 (2014), pp. 564575, DOI: $10.1177 / 0954411914537476$.

Clarke, H. D. and Hentz, J. G., Restoration of femoral anatomy in TKA with unisex and gender-specific components, Clinical orthopaedics and related research, Vol. 466, No. 11 (2008), pp. 2711-2716, DOI: 10.1007/s11999-0080454-6.

Clement, N. D. and Deehan, D. J., Knee biomechanics: Will we ever know the truth?, Bone \& joint research, Vol. 7, No. 5 (2018), pp. 325-326, DOI: 10.1302/2046-3758.75.Bjr-2017-0360.

Conley, S., Rosenberg, A. and Crowninshield, R., The female knee: anatomic variations, Journal of the American Academy of Orthopaedic Surgeons, Vol. 15 Suppl 1, (2007), pp. S31-36.

D'Lima, D. D. and Colwell, C. W., Intraoperative Measurements and Tools to Assess Stability, Journal of the American Academy of Orthopaedic Surgeons, Vol. 25 Suppl 1， (2017), pp. S29-s32, DOI: 10.5435/jaaos-d-16-00629.

Dall'Oca, C., Ricci, M., Vecchini, E., Giannini, N., Lamberti, D., Tromponi, C. and Magnan, B., Evolution of TKA design, Acta BioMedica Vol. 88, No. 2s (2017), pp. 17-31, DOI: 10.23750/abm.v88i2 -S.6508.

Dalury, D. F., Pomeroy, D. L., Gorab, R. S. and Adams, M. J., Why are total knee arthroplasties being revised?, The Journal of arthroplasty, Vol. 28, No. 8 Suppl (2013), pp. 120-121, DOI: 10.1016/j.arth.2013.04.051.

Dargahi, J., Najarian, S. and Amiri, S., Optimization of the geometry of total knee implant in the sagittal plane using FEA, Bio-medical materials and engineering, Vol. 13, No. 4 (2003), pp. 439-449.

Dejour, D., Deschamps, G., Garotta, L. and Dejour, H., Laxity in posterior cruciate sparing and posterior stabilized total knee prostheses, Clinical orthopaedics and related research, No. 364 (1999), pp. 182-193, DOI: 10.1097/00003086199907000-00024.

Dorr, L. D., Ochsner, J. L., Gronley, J. and Perry, J., Functional comparison of posterior cruciate-retained versus cruciatesacrificed total knee arthroplasty, Clinical orthopaedics and related research, No. 236 (1988), pp. 36-43.

Essner, A., Herrera, L., Hughes, P. and Kester, M., The influence of material and design on total knee replacement wear, The journal of knee surgery, Vol. 24, No. 01 (2011), pp. 009-018.

Essner, A., Klein, R., Bushelow, M., Wang, A., Kvitnitsky, M. and Mahoney, O., The effect of sagittal conformity on 
knee wear, Wear, Vol. 255, No. 7 (2003), pp. 1085-1092, DOI: 10.1016/S0043-1648(03)00172-8.

Fitzpatrick, C. K., Baldwin, M. A., Ali, A. A., Laz, P. J. and Rullkoetter, P. J., Comparison of patellar bone strain in the natural and implanted knee during simulated deep flexion, Journal of Orthopaedic Research, Vol. 29, No. 2 (2011a), pp. 232-239, DOI: 10.1002/jor.21211.

Fitzpatrick, C. K., Baldwin, M. A., Laz, P. J., FitzPatrick, D. P., Lerner, A. L. and Rullkoetter, P. J., Development of a statistical shape model of the patellofemoral joint for investigating relationships between shape and function, Journal of biomechanics, Vol. 44, No. 13 (2011b), pp. 2446-2452, DOI: 10.1016/j.jbiomech.2011.06.025.

Fitzpatrick, C. K., Baldwin, M. A. and Rullkoetter, P. J., Computationally efficient finite element evaluation of natural patellofemoral mechanics, Journal of biomechanical engineering, Vol. 132, No. 12 (2010), pp. 121013, DOI: $10.1115 / 1.4002854$.

Fitzpatrick, C. K., Baldwin, M. A., Rullkoetter, P. J. and Laz, P. J., Combined probabilistic and principal component analysis approach for multivariate sensitivity evaluation and application to implanted patellofemoral mechanics, Journal of biomechanics, Vol. 44, No. 1 (2011c), pp. 13-21, DOI: 10.1016/j.jbiomech.2010.08.016.

Fitzpatrick, C. K., Clary, C. W., Cyr, A. J., Maletsky, L. P. and Rullkoetter, P. J., Mechanics of post-cam engagement during simulated dynamic activity, Journal of Orthopaedic Research, Vol. 31, No. 9 (2013), pp. 1438-1446, DOI: 10.1002/jor.22366.

Fitzpatrick, C. K., Hemelaar, P. and Taylor, M., Computationally efficient prediction of bone-implant interface micromotion of a cementless tibial tray during gait, Journal of biomechanics, Vol. 47, No. 7 (2014), pp. 1718-1726, DOI: $10.1016 /$ j.jbiomech.2014.02.018.

Fitzpatrick, C. K., Steensen, R. N., Tumuluri, A., Trinh, T., Bentley, J. and Rullkoetter, P. J., Computational analysis of factors contributing to patellar dislocation, Journal of Orthopaedic Research, Vol. 34, No. 3 (2016), pp. 444-453, DOI: $10.1002 /$ jor.23041.

Flores-Hernandez, C., Netter, J., Hermida, J., Steklov, N., Kester, M. and D. D'Lima, D., Prediction of Wear in Crosslinked Polyethylene Unicompartmental Knee Arthroplasty, Lubricants, Vol. 2015, (2015), pp. 381-393, DOI: 10.3390/lubricants3020381.

Foote, J. A., Smith, H. K., Jonas, S. C., Greenwood, R. and Weale, A. E., Return to work following knee arthroplasty, The Knee, Vol. 17, No. 1 (2010), pp. 19-22, DOI: 10.1016/j.knee.2009.06.001.

Freeman, M. A. and Pinskerova, V., The movement of the normal tibio-femoral joint, Journal of biomechanics, Vol. 38, No. 2 (2005), pp. 197-208.

Freeman, M. A. and Railton, G. T., Should the posterior cruciate ligament be retained or resected in condylar nonmeniscal knee arthroplasty? The case for resection, The Journal of arthroplasty, Vol. 3 Suppl, (1988), pp. S3-12.

Fregly, B. J., Sawyer, W. G., Harman, M. K. and Banks, S. A., Computational wear prediction of a total knee replacement from in vivo kinematics, Journal of biomechanics, Vol. 38, No. 2 (2005), pp. 305-314, DOI: 10.1016/j.jbiomech.2004.02.013.

Furnes, O., Espehaug, B., Lie, S. A., Vollset, S. E., Engesaeter, L. B. and Havelin, L. I., Failure mechanisms after unicompartmental and tricompartmental primary knee replacement with cement, Journal of Bone and Joint SurgeryAmerican, Vol. 89, No. 3 (2007), pp. 519-525, DOI: 10.2106/jbjs.F.00210.

Godest, A. C., Beaugonin, M., Haug, E., Taylor, M. and Gregson, P. J., Simulation of a knee joint replacement during a gait cycle using explicit finite element analysis, Journal of biomechanics, Vol. 35, No. 2 (2002), pp. 267-275.

Gollehon, D. L., Torzilli, P. A. and Warren, R. F., The role of the posterolateral and cruciate ligaments in the stability of the human knee. A biomechanical study, Journal of Bone and Joint Surgery-American Vol. 69, No. 2 (1987), pp. 233-242.

Greene, K. A., Gender-specific design in total knee arthroplasty, The Journal of arthroplasty, Vol. 22, No. 7 Suppl 3 (2007), pp. 27-31, DOI: 10.1016/j.arth.2007.05.019.

Ha, J. K., Shim, J. C., Kim, D. W., Lee, Y. S., Ra, H. J. and Kim, J. G., Relationship between meniscal extrusion and various clinical findings after meniscus allograft transplantation, The American journal of sports medicine, Vol. 38, No. 12 (2010), pp. 2448-2455, DOI: 10.1177/0363546510375550.

Halloran, J. P., Petrella, A. J. and Rullkoetter, P. J., Explicit finite element modeling of total knee replacement mechanics, Journal of biomechanics, Vol. 38, No. 2 (2005), pp. 323-331, DOI: 10.1016/j.jbiomech.2004.02.046.

Harrysson, O. L., Hosni, Y. A. and Nayfeh, J. F., Custom-designed orthopedic implants evaluated using finite element analysis of patient-specific computed tomography data: femoral-component case study, BMC musculoskeletal 
disorders, Vol. 8, (2007), pp. 91, DOI: 10.1186/1471-2474-8-91.

Hitt, K., Shurman, J. R., 2nd, Greene, K., McCarthy, J., Moskal, J., Hoeman, T. and Mont, M. A., Anthropometric measurements of the human knee: correlation to the sizing of current knee arthroplasty systems, Journal of Bone and Joint Surgery-American, Vol. 85-A Suppl 4, (2003), pp. 115-122.

Huang, C. H., Liau, J. J., Huang, C. H. and Cheng, C. K., Influence of post-cam design on stresses on posterior-stabilized tibial posts, Clinical orthopaedics and related research, Vol. 450, (2006), pp. 150-156, DOI: 10.1097/01.blo.0000218739.76871.28.

Huang, C. H., Liau, J. J., Huang, C. H. and Cheng, C. K., Stress analysis of the anterior tibial post in posterior stabilized knee prostheses, Journal of Orthopaedic Research, Vol. 25, No. 4 (2007), pp. 442-449, DOI: 10.1002/jor.20336.

Iesaka, K., Tsumura, H., Sonoda, H., Sawatari, T., Takasita, M. and Torisu, T., The effects of tibial component inclination on bone stress after unicompartmental knee arthroplasty, Journal of biomechanics, Vol. 35, No. 7 (2002), pp. 969 974.

Incavo, S. J., Ronchetti, P. J., Howe, J. G. and Tranowski, J. P., Tibial plateau coverage in total knee arthroplasty, Clinical orthopaedics and related research, No. 299 (1994), pp. 81-85.

Innocenti, B., Bilgen, O. F., Labey, L., van Lenthe, G. H., Sloten, J. V. and Catani, F., Load sharing and ligament strains in balanced, overstuffed and understuffed UKA. A validated finite element analysis, The Journal of arthroplasty, Vol. 29, No. 7 (2014), pp. 1491-1498, DOI: 10.1016/j.arth.2014.01.020.

Innocenti, B., Pianigiani, S., Ramundo, G. and Thienpont, E., Biomechanical Effects of Different Varus and Valgus Alignments in Medial Unicompartmental Knee Arthroplasty, The Journal of arthroplasty, Vol. 31, No. 12 (2016), pp. 2685-2691, DOI: 10.1016/j.arth.2016.07.006.

Inoue, S., Akagi, M., Asada, S., Mori, S., Zaima, H. and Hashida, M., The Valgus Inclination of the Tibial Component Increases the Risk of Medial Tibial Condylar Fractures in Unicompartmental Knee Arthroplasty, The Journal of arthroplasty, Vol. 31, No. 9 (2016), pp. 2025-2030, DOI: 10.1016/j.arth.2016.02.043.

Ishii, Y., Terajima, K., Koga, Y., Takahashi, H. E., Bechtold, J. E. and Gustilo, R. B., Gait analysis after total knee arthroplasty. Comparison of posterior cruciate retention and substitution, Journal of Orthopaedic Science, Vol. 3, No. 6 (1998), pp. 310-317.

Jeer, P. J., Cossey, A. J. and Keene, G. C., Haemoglobin levels following unicompartmental knee arthroplasty: influence of transfusion practice and surgical approach, The Knee, Vol. 12, No. 5 (2005), pp. 358-361, DOI: 10.1016/j.knee.2004.11.006.

Johnson, S., Jones, P. and Newman, J. H., The survivorship and results of total knee replacements converted from unicompartmental knee replacements, The Knee, Vol. 14, No. 2 (2007), pp. 154-157, DOI: 10.1016/j.knee.2006.11.012.

Jones, C. A., Beaupre, L. A., Johnston, D. W. and Suarez-Almazor, M. E., Total joint arthroplasties: current concepts of patient outcomes after surgery, Rheumatic diseases clinics of North America, Vol. 33, No. 1 (2007), pp. 71-86, DOI: 10.1016/j.rdc.2006.12.008.

Kang, K.-T., Koh, Y.-G., Son, J., Kim, S.-J., Choi, S., Jung, M. and Kim, S.-H., Finite element analysis of the biomechanical effects of 3 posterolateral corner reconstruction techniques for the knee joint, The Journal of arthroplasty, Vol. 33, No. 8 (2017a), pp. 1537-1550.

Kang, K.-T., Koh, Y.-G., Son, J., Yeom, J. S., Park, J.-H. and Kim, H.-J., Biomechanical evaluation of pedicle screw fixation system in spinal adjacent levels using polyetheretherketone, carbon-fiber-reinforced polyetheretherketone, and traditional titanium as rod materials, Composites Part B: Engineering, Vol. 130, (2017b), pp. 248-256, DOI: 10.1016/j.compositesb.2017.07.052.

Kang, K.-T., Kwon, S. K., Son, J., Kwon, O.-R., Lee, J.-S. and Koh, Y.-G., The increase in posterior tibial slope provides a positive biomechanical effect in posterior-stabilized total knee arthroplasty, Knee surgery, sports traumatology, arthroscopy : official journal of the ESSKA, Vol. 26, No. 10 (2018a), pp. 3188-3195, DOI: 10.1007/s00167-0184925-3.

Kang, K.-T., Son, J., Kim, H.-J., Baek, C., Kwon, O.-R. and Koh, Y.-G., Wear predictions for UHMWPE material with various surface properties used on the femoral component in total knee arthroplasty: a computational simulation study, Journal of Materials Science: Materials in Medicine, Vol. 28, No. 7 (2017c), pp. 105.

Kang, K. T., Kim, S. H., Son, J., Lee, Y. H. and Chun, H. J., Probabilistic Approach for Determining the Material Properties of Meniscal Attachments In Vivo Using Magnetic Resonance Imaging and a Finite Element Model, 
Journal of Computational Biology, Vol. 22, No. 12 (2015), pp. 1097-1107, DOI: 10.1089/cmb.2015.0126.

Kang, K. T., Kim, S. H., Son, J., Lee, Y. H., Kim, S. and Chun, H. J., Probabilistic evaluation of the material properties of the in vivo subject-specific articular surface using a computational model, Journal of biomedical materials research. Part B, Applied biomaterials, Vol. 105, No. 6 (2017d), pp. 1390-1400, DOI: 10.1002/jbm.b.33666.

Kang, K. T., Koh, Y. G., Jung, M., Nam, J. H., Son, J., Lee, Y. H., Kim, S. J. and Kim, S. H., The effects of posterior cruciate ligament deficiency on posterolateral corner structures under gait- and squat-loading conditions: A computational knee model, Bone \& joint research, Vol. 6, No. 1 (2017e), pp. 31-42, DOI: 10.1302/20463758.61.Bjr-2016-0184.R1.

Kang, K. T., Koh, Y. G., Nam, J. H., Kwon, S. K. and Park, K. K., Kinematic Alignment in Cruciate Retaining Implants Improves the Biomechanical Function in Total Knee Arthroplasty during Gait and Deep Knee Bend, The journal of knee surgery (2019a), DOI: 10.1055/s-0039-1677846.

Kang, K. T., Koh, Y. G., Son, J., Kwon, O. R., Baek, C., Jung, S. H. and Park, K. K., Measuring the effect of femoral malrotation on knee joint biomechanics for total knee arthroplasty using computational simulation, Bone \& joint research, Vol. 5, No. 11 (2016), pp. 552-559, DOI: 10.1302/2046-3758.511.Bjr-2016-0107.R1.

Kang, K. T., Koh, Y. G., Son, J., Kwon, O. R., Lee, J. S. and Kwon, S. K., Biomechanical Effects of Posterior Condylar Offset and Posterior Tibial Slope on Quadriceps Force and Joint Contact Forces in Posterior-Stabilized Total Knee Arthroplasty, BioMed research international (2017f), pp. 4908639, DOI: 10.1155/2017/4908639.

Kang, K. T., Koh, Y. G., Son, J., Kwon, O. R., Lee, J. S. and Kwon, S. K., Comparison of Kinematics in Cruciate Retaining and Posterior Stabilized for Fixed and Rotating Platform Mobile-Bearing Total Knee Arthroplasty with respect to Different Posterior Tibial Slope, BioMed research international (2018b), pp. 5139074, DOI: 10.1155/2018/5139074.

Kang, K. T., Koh, Y. G., Son, J., Kwon, O. R., Lee, J. S. and Kwon, S. K., A computational simulation study to determine the biomechanical influence of posterior condylar offset and tibial slope in cruciate retaining total knee arthroplasty, Bone \& joint research, Vol. 7, No. 1 (2018c), pp. 69-78, DOI: 10.1302/2046-3758.71.Bjr-2017-0143.R1.

Kang, K. T., Koh, Y. G., Son, J., Kwon, O. R., Lee, J. S. and Kwon, S. K., Influence of Increased Posterior Tibial Slope in Total Knee Arthroplasty on Knee Joint Biomechanics: A Computational Simulation Study, The Journal of arthroplasty, Vol. 33, No. 2 (2018d), pp. 572-579, DOI: 10.1016/j.arth.2017.09.025.

Kang, K. T., Koh, Y. G., Son, J., Kwon, O. R. and Park, K. K., Flexed femoral component improves kinematics and biomechanical effect in posterior stabilized total knee arthroplasty, Knee surgery, sports traumatology, arthroscopy : official journal of the ESSKA (2018e), DOI: 10.1007/s00167-018-5093-1.

Kang, K. T., Kwon, O. R., Son, J., Suh, D. S., Kwon, S. K. and Koh, Y. G., Effect of joint line preservation on mobiletype bearing unicompartmental knee arthroplasty: finite element analysis, Australasian Physical and Engineering Science in Medicine, Vol. 41, No. 1 (2018f), pp. 201-208, DOI: 10.1007/s13246-018-0630-2.

Kang, K. T., Kwon, S. K., Kwon, O. R., Lee, J. S. and Koh, Y. G., Comparison of the biomechanical effect of posterior condylar offset and kinematics between posterior cruciate-retaining and posterior-stabilized total knee arthroplasty, The Knee, Vol. 26, No. 1 (2019b), pp. 250-257, DOI: 10.1016/j.knee.2018.11.017.

Kang, K. T., Kwon, S. K., Son, J., Kwon, O. R., Lee, J. S. and Koh, Y. G., Effects of posterior condylar offset and posterior tibial slope on mobile-bearing total knee arthroplasty using computational simulation, The Knee, Vol. 25, No. 5 (2018g), pp. 903-914, DOI: 10.1016/j.knee.2018.06.011.

Kang, K. T., Park, J. H., Koh, Y. G., Shin, J. and Park, K. K., Biomechanical effects of posterior tibial slope on unicompartmental knee arthroplasty using finite element analysis, Bio-medical materials and engineering, Vol. 30, No. 2 (2019c), pp. 133-144, DOI: 10.3233/bme-191039.

Kang, K. T., Son, J., Baek, C., Kwon, O. R. and Koh, Y. G., Femoral component alignment in unicompartmental knee arthroplasty leads to biomechanical change in contact stress and collateral ligament force in knee joint, Archives of orthopaedic and trauma surgery, Vol. 138, No. 4 (2018h), pp. 563-572, DOI: 10.1007/s00402-018-2884-2.

Kang, K. T., Son, J., Koh, Y. G., Kwon, O. R., Kwon, S. K., Lee, Y. J. and Park, K. K., Effect of femoral component position on biomechanical outcomes of unicompartmental knee arthroplasty, The Knee, Vol. 25, No. 3 (2018i), pp. 491-498, DOI: 10.1016/j.knee.2018.03.003.

Kang, K. T., Son, J., Kwon, S. K., Kwon, O. R. and Koh, Y. G., Preservation of femoral and tibial coronal alignment to improve biomechanical effects of medial unicompartment knee arthroplasty: Computational study, Bio-medical materials and engineering, Vol. 29, No. 5 (2018j), pp. 651-664, DOI: 10.3233/bme-181015.

Kang, K. T., Son, J., Suh, D. S., Kwon, S. K., Kwon, O. R. and Koh, Y. G., Patient-specific medial unicompartmental 
knee arthroplasty has a greater protective effect on articular cartilage in the lateral compartment: A Finite Element Analysis, Bone \& joint research, Vol. 7, No. 1 (2018k), pp. 20-27, DOI: 10.1302/2046-3758.71.Bjr-2017-0115.R2.

Keyes, G. W., Carr, A. J., Miller, R. K. and Goodfellow, J. W., The radiographic classification of medial gonarthrosis. Correlation with operation methods in 200 knees, Acta orthopaedica Scandinavica, Vol. 63, No. 5 (1992), pp. 497 501.

Kiapour, A., Kiapour, A. M., Kaul, V., Quatman, C. E., Wordeman, S. C., Hewett, T. E., Demetropoulos, C. K. and Goel, V. K., Finite element model of the knee for investigation of injury mechanisms: development and validation, Journal of biomechanical engineering, Vol. 136, No. 1 (2014), pp. 011002, DOI: 10.1115/1.4025692.

Kim, Y. H., Kwon, O. S. and Kim, K., Analysis of biomechanical effect of stem-end design in revision TKA using Digital Korean model, Clinical Biomechanics (Bristol, Avon), Vol. 23, No. 7 (2008), pp. 853-858, DOI: 10.1016/j.clinbiomech.2008.01.010.

Knight, L. A., Pal, S., Coleman, J. C., Bronson, F., Haider, H., Levine, D. L., Taylor, M. and Rullkoetter, P. J., Comparison of long-term numerical and experimental total knee replacement wear during simulated gait loading, Journal of biomechanics, Vol. 40, No. 7 (2007), pp. 1550-1558.

Koh, Y. G., Lee, J. A., Chung, P. K. and Kang, K. T., Computational analysis of customized cruciate retaining total knee arthroplasty restoration of native knee joint biomechanics, Artificial organs, Vol. 43, No. 5 (2019a), pp. 504-514, DOI: 10.1111/aor.13382.

Koh, Y. G., Nam, J. H., Chung, H. S., Kim, H. J., Chun, H. J. and Kang, K. T., Gender differences in morphology exist in posterior condylar offsets of the knee in Korean population, Knee surgery, sports traumatology, arthroscopy : official journal of the ESSKA, Vol. 27, No. 5 (2019b), pp. 1628-1634, DOI: 10.1007/s00167-018-5259-x.

Koh, Y. G., Nam, J. H., Chung, H. S., Lee, H. Y., Kim, H. J., Kim, H. J. and Kang, K. T., Gender-related morphological differences in sulcus angle and condylar height for the femoral trochlea using magnetic resonance imaging, Knee surgery, sports traumatology, arthroscopy : official journal of the ESSKA (2019c), DOI: 10.1007/s00167-01905423-4.

Koh, Y. G., Nam, J. H. and Kang, K. T., Effect of geometric variations on tibiofemoral surface and post-cam design of normal knee kinematics restoration, Journal of experimental orthopaedics, Vol. 5, No. 1 (2018a), pp. 53, DOI: 10.1186/s40634-018-0167-z.

Koh, Y. G., Park, K. M., Lee, H. Y. and Kang, K. T., Influence of tibiofemoral congruency design on the wear of patientspecific unicompartmental knee arthroplasty using finite element analysis, Bone \& joint research, Vol. 8, No. 3 (2019d), pp. 156-164, DOI: 10.1302/2046-3758.83.Bjr-2018-0193.R1.

Koh, Y. G., Park, K. M., Lee, J. A., Nam, J. H., Lee, H. Y. and Kang, K. T., Total knee arthroplasty application of polyetheretherketone and carbon-fiber-reinforced polyetheretherketone: A review, Materials science \& engineering. C, Materials for biological applications, Vol. 100 (2019e), pp. 70-81, DOI: 10.1016/j.msec.2019.02.082.

Koh, Y. G., Son, J., Kwon, O. R., Kwon, S. K. and Kang, K. T., Effect of Post-Cam Design for Normal Knee Joint Kinematic, Ligament, and Quadriceps Force in Patient-Specific Posterior-Stabilized Total Knee Arthroplasty by Using Finite Element Analysis, BioMed research international (2018b), pp. 2438980, DOI: 10.1155/2018/2438980.

Koh, Y. G., Son, J., Kwon, O. R., Kwon, S. K. and Kang, K. T., Patient-specific design for articular surface conformity to preserve normal knee mechanics in posterior stabilized total knee arthroplasty, Bio-medical materials and engineering, Vol. 29, No. 4 (2018c), pp. 401-414, DOI: 10.3233/bme-180998.

Koh, Y. G., Son, J., Kwon, O. R., Kwon, S. K. and Kang, K. T., Tibiofemoral conformity variation offers changed kinematics and wear performance of customized posterior-stabilized total knee arthroplasty, Knee surgery, sports traumatology, arthroscopy : official journal of the ESSKA, Vol. 27, No. 4 (2019f), pp. 1213-1223, DOI: 10.1007/s00167-018-5045-9.

Koh, Y. G., Son, J., Kwon, S. K., Kim, H. J., Kwon, O. R. and Kang, K. T., Preservation of kinematics with posterior cruciate-, bicruciate- and patient-specific bicruciate-retaining prostheses in total knee arthroplasty by using computational simulation with normal knee model, Bone \& joint research, Vol. 6, No. 9 (2017), pp. 557-565, DOI: 10.1302/2046-3758.69.Bjr-2016-0250.R1.

Kuriyama, S., Ishikawa, M., Furu, M., Ito, H. and Matsuda, S., Malrotated tibial component increases medial collateral ligament tension in total knee arthroplasty, Journal of Orthopaedic Research, Vol. 32, No. 12 (2014), pp. 1658-1666, DOI: $10.1002 /$ jor.22711.

Kwon, O. R., Kang, K. T., Son, J., Kwon, S. K., Jo, S. B., Suh, D. S., Choi, Y. J., Kim, H. J. and Koh, Y. G., Biomechanical 
comparison of fixed- and mobile-bearing for unicomparmental knee arthroplasty using finite element analysis, Journal of Orthopaedic Research, Vol. 32, No. 2 (2014), pp. 338-345, DOI: 10.1002/jor.22499.

Kwon, O. R., Kang, K. T., Son, J., Suh, D. S., Baek, C. and Koh, Y. G., Importance of joint line preservation in unicompartmental knee arthroplasty: Finite element analysis, Journal of Orthopaedic Research, Vol. 35, No. 2 (2017), pp. 347-352, DOI: 10.1002/jor.23279.

LaPrade, R. F. and Wentorf, F., Diagnosis and treatment of posterolateral knee injuries, Clinical orthopaedics and related research, No. 402 (2002), pp. 110-121.

Laurencin, C. T., Zelicof, S. B., Scott, R. D. and Ewald, F. C., Unicompartmental versus total knee arthroplasty in the same patient. A comparative study, Clinical orthopaedics and related research, No. 273 (1991), pp. 151-156.

Laz, P. J. and Browne, M., A review of probabilistic analysis in orthopaedic biomechanics, Proceedings of the Institution of Mechanical Engineers, Part H: Journal of Engineering in Medicine, Vol. 224, No. 8 (2010), pp. 927-943, DOI: 10.1243/09544119jeim739.

Lingard, E. A., Katz, J. N., Wright, E. A. and Sledge, C. B., Predicting the outcome of total knee arthroplasty, Journal of Bone and Joint Surgery-American, Vol. 86, No. 10 (2004), pp. 2179-2186.

MacDonald, S. J., Charron, K. D., Bourne, R. B., Naudie, D. D., McCalden, R. W. and Rorabeck, C. H., The John Insall Award: gender-specific total knee replacement: prospectively collected clinical outcomes, Clinical orthopaedics and related research, Vol. 466, No. 11 (2008), pp. 2612-2616, DOI: 10.1007/s11999-008-0430-1.

Mahfouz, M. R., Merkl, B. C., Fatah, E. E., Booth, R., Jr. and Argenson, J. N., Automatic methods for characterization of sexual dimorphism of adult femora: distal femur, Computer methods in biomechanics and biomedical engineering, Vol. 10, No. 6 (2007), pp. 447-456, DOI: 10.1080/10255840701552093.

Makris, E. A., Hadidi, P. and Athanasiou, K. A., The knee meniscus: structure-function, pathophysiology, current repair techniques, and prospects for regeneration, Biomaterials, Vol. 32, No. 30 (2011), pp. 7411-7431, DOI: 10.1016/j.biomaterials.2011.06.037.

Marra, M. A., Strzelczak, M., Heesterbeek, P. J. C., van de Groes, S. A. W., Janssen, D. W., Koopman, B., Wymenga, A. B. and Verdonschot, N. J. J., Anterior referencing of tibial slope in total knee arthroplasty considerably influences knee kinematics: a musculoskeletal simulation study, Knee Surgery, Sports Traumatology, Arthroscopy, Vol. 26, No. 5 (2018), pp. 1540-1548, DOI: 10.1007/s00167-017-4561-3.

Martelli, S., Ellis, R. E., Marcacci, M. and Zaffagnini, S., Total knee arthroplasty kinematics. Computer simulation and intraoperative evaluation, The Journal of arthroplasty, Vol. 13, No. 2 (1998), pp. 145-155.

Merchant, A. C., Arendt, E. A., Dye, S. F., Fredericson, M., Grelsamer, R. P., Leadbetter, W. B., Post, W. R. and Teitge, R. A., The female knee: anatomic variations and the female-specific total knee design, Clinical orthopaedics and related research, Vol. 466, No. 12 (2008), pp. 3059-3065, DOI: 10.1007/s11999-008-0536-5.

Mont, M. A., Marker, D. R., Seyler, T. M., Jones, L. C., Kolisek, F. R. and Hungerford, D. S., High-impact sports after total knee arthroplasty, The Journal of arthroplasty, Vol. 23, No. 6 Suppl 1 (2008), pp. 80-84, DOI: 10.1016/j.arth.2008.04.018.

Moro-oka, T. A., Muenchinger, M., Canciani, J. P. and Banks, S. A., Comparing in vivo kinematics of anterior cruciateretaining and posterior cruciate-retaining total knee arthroplasty, Knee Surgery, Sports Traumatology, Arthroscopy, Vol. 15, No. 1 (2007), pp. 93-99, DOI: 10.1007/s00167-006-0134-6.

Morra, E. A. and Greenwald, A. S., Effects of walking gait on ultra-high molecular weight polyethylene damage in unicompartmental knee systems. A finite element study, Journal of Bone and Joint Surgery-American, Vol. 85-A Suppl 4, (2003), pp. 111-114.

Morra, E. A. and Greenwald, A. S., Polymer insert stress in total knee designs during high-flexion activities: a finite element study, Journal of Bone and Joint Surgery-American, Vol. 87 Suppl 2, (2005), pp. 120-124, DOI: 10.2106/jbjs.E.00436.

Nakamura, S., Tian, Y., Tanaka, Y., Kuriyama, S., Ito, H., Furu, M. and Matsuda, S., The effects of kinematically aligned total knee arthroplasty on stress at the medial tibia: A case study for varus knee, Bone \& joint research, Vol. 6, No. 1 (2017), pp. 43-51, DOI: 10.1302/2046-3758.61.Bjr-2016-0090.R1.

Netter, J., Hermida, J. C., D’Alessio, J., Kester, M. and D'Lima, D. D., Effect of polyethylene crosslinking and bearing design on wear of unicompartmental arthroplasty, The Journal of arthroplasty, Vol. 30, No. 8 (2015), pp. 1430-1433.

Noble, P. C., Conditt, M. A., Cook, K. F. and Mathis, K. B., The John Insall Award: Patient expectations affect satisfaction with total knee arthroplasty, Clinical orthopaedics and related research, Vol. 452 (2006), pp. 35-43, DOI: 
10.1097/01.blo.0000238825.63648.1e.

Noble, P. C., Gordon, M. J., Weiss, J. M., Reddix, R. N., Conditt, M. A. and Mathis, K. B., Does total knee replacement restore normal knee function?, Clinical orthopaedics and related research, No. 431 (2005), pp. 157-165.

Park, K. K., Koh, Y. G., Park, K. M., Park, J. H. and Kang, K. T., Biomechanical effect with respect to the sagittal positioning of the femoral component in unicompartmental knee arthroplasty, Bio-medical materials and engineering, Vol. 30, No. 2 (2019), pp. 171-182, DOI: 10.3233/bme-191042.

Patil, S., Colwell, C. W., Jr., Ezzet, K. A. and D'Lima, D. D., Can normal knee kinematics be restored with unicompartmental knee replacement?, Journal of Bone and Joint Surgery-American Vol. 87, No. 2 (2005), pp. 332338, DOI: 10.2106/jbjs.C.01467.

Pegg, E. C., Walter, J., Mellon, S. J., Pandit, H. G., Murray, D. W., D'Lima, D. D., Fregly, B. J. and Gill, H. S., Evaluation of factors affecting tibial bone strain after unicompartmental knee replacement, Journal of Orthopaedic Research, Vol. 31, No. 5 (2013), pp. 821-828, DOI: 10.1002/jor.22283.

Perillo-Marcone, A. and Taylor, M., Effect of varus/valgus malalignment on bone strains in the proximal tibia after TKR: an explicit finite element study, Journal of biomechanical engineering, Vol. 129, No. 1 (2007), pp. 1-11, DOI: 10.1115/1.2401177.

Price, A. J. and Svard, U., A second decade lifetable survival analysis of the Oxford unicompartmental knee arthroplasty, Clinical orthopaedics and related research, Vol. 469, No. 1 (2011), pp. 174-179, DOI: 10.1007/s11999-010-1506-2.

Riddle, D. L., Jiranek, W. A. and McGlynn, F. J., Yearly incidence of unicompartmental knee arthroplasty in the United States, The Journal of arthroplasty, Vol. 23, No. 3 (2008), pp. 408-412, DOI: 10.1016/j.arth.2007.04.012.

Rong, G. W. and Wang, Y. C., The role of cruciate ligaments in maintaining knee joint stability, Clinical orthopaedics and related research, No. 215 (1987), pp. 65-71.

Rullkoetter, P. J., Fitzpatrick, C. K. and Clary, C. W., How Can We Use Computational Modeling to Improve Total Knee Arthroplasty? Modeling Stability and Mobility in the Implanted Knee, Journal of the American Academy of Orthopaedic Surgeons, Vol. 25 Suppl 1 (2017), pp. S33-s39, DOI: 10.5435/jaaos-d-16-00640.

Sathasivam, S. and Walker, P. S., Optimization of the bearing surface geometry of total knees, Journal of biomechanics, Vol. 27, No. 3 (1994), pp. 255-264.

Sathasivam, S. and Walker, P. S., Computer model to predict subsurface damage in tibial inserts of total knees, Journal of Orthopaedic Research, Vol. 16, No. 5 (1998), pp. 564-571, DOI: 10.1002/jor.1100160507.

Sathasivam, S., Walker, P. S., Campbell, P. A. and Rayner, K., The effect of contact area on wear in relation to fixed bearing and mobile bearing knee replacements, Journal of biomedical materials research, Vol. 58, No. 3 (2001), pp. 282-290.

Schroer, W. C., Berend, K. R., Lombardi, A. V., Barnes, C. L., Bolognesi, M. P., Berend, M. E., Ritter, M. A. and Nunley, R. M., Why are total knees failing today? Etiology of total knee revision in 2010 and 2011, The Journal of arthroplasty, Vol. 28, No. 8 Suppl (2013), pp. 116-119, DOI: 10.1016/j.arth.2013.04.056.

Schwarzkopf, R., Brodsky, M., Garcia, G. A. and Gomoll, A. H., Surgical and Functional Outcomes in Patients Undergoing Total Knee Replacement With Patient-Specific Implants Compared With "Off-the-Shelf" Implants, Orthopaedic journal of sports medicine, Vol. 3, No. 7 (2015), pp. 2325967115590379, DOI: $10.1177 / 2325967115590379$.

Shelburne, K. B., Pandy, M. G., Anderson, F. C. and Torry, M. R., Pattern of anterior cruciate ligament force in normal walking, Journal of biomechanics, Vol. 37, No. 6 (2004), pp. 797-805, DOI: 10.1016/j.jbiomech.2003.10.010.

Simpson, D. J., Price, A. J., Gulati, A., Murray, D. W. and Gill, H. S., Elevated proximal tibial strains following unicompartmental knee replacement--a possible cause of pain, Medical engineering \& physics, Vol. 31, No. 7 (2009), pp. 752-757, DOI: 10.1016/j.medengphy.2009.02.004.

Smoger, L. M., Fitzpatrick, C. K., Clary, C. W., Cyr, A. J., Maletsky, L. P., Rullkoetter, P. J. and Laz, P. J., Statistical modeling to characterize relationships between knee anatomy and kinematics, Journal of Orthopaedic Research, Vol. 33, No. 11 (2015), pp. 1620-1630, DOI: 10.1002/jor.22948.

Smoger, L. M., Shelburne, K. B., Cyr, A. J., Rullkoetter, P. J. and Laz, P. J., Statistical shape modeling predicts patellar bone geometry to enable stereo-radiographic kinematic tracking, Journal of biomechanics, Vol. 58 (2017), pp. 187194, DOI: 10.1016/j.jbiomech.2017.05.009.

Song, E. K., Seon, J. K., Moon, J. Y. and Ji-Hyoun, Y., The evolution of modern total knee prostheses (2013), p.183194, IntechOpen, . 
Stiehl, J. B., Komistek, R. D., Cloutier, J. M. and Dennis, D. A., The cruciate ligaments in total knee arthroplasty: a kinematic analysis of 2 total knee arthroplasties, The Journal of arthroplasty, Vol. 15, No. 5 (2000), pp. 545-550.

Suh, D. S., Kang, K. T., Son, J., Kwon, O. R., Baek, C. and Koh, Y. G., Computational study on the effect of malalignment of the tibial component on the biomechanics of total knee arthroplasty: A Finite Element Analysis, Bone \& joint research, Vol. 6, No. 11 (2017), pp. 623-630, DOI: 10.1302/2046-3758.611.Bjr-2016-0088.R2.

Taylor, M., Bryan, R. and Galloway, F., Accounting for patient variability in finite element analysis of the intact and implanted hip and knee: a review, International journal for numerical methods in biomedical engineering, Vol. 29, No. 2 (2013), pp. 273-292, DOI: 10.1002/cnm.2530.

Taylor, M. and Prendergast, P. J., Four decades of finite element analysis of orthopaedic devices: where are we now and what are the opportunities?, Journal of biomechanics, Vol. 48, No. 5 (2015), pp. 767-778, DOI: 10.1016/j.jbiomech.2014.12.019.

Thompson, J. A., Hast, M. W., Granger, J. F., Piazza, S. J. and Siston, R. A., Biomechanical effects of total knee arthroplasty component malrotation: a computational simulation, Journal of Orthopaedic Research, Vol. 29, No. 7 (2011), pp. 969-975, DOI: 10.1002/jor.21344.

Varadarajan, K. M., Zumbrunn, T., Rubash, H. E., Malchau, H., Li, G. and Muratoglu, O. K., Cruciate Retaining Implant With Biomimetic Articular Surface to Reproduce Activity Dependent Kinematics of the Normal Knee, The Journal of arthroplasty, Vol. 30, No. 12 (2015a), pp. 2149-2153.e2142, DOI: 10.1016/j.arth.2015.06.018.

Varadarajan, K. M., Zumbrunn, T., Rubash, H. E., Malchau, H., Muratoglu, O. K. and Li, G., Reverse Engineering Nature to Design Biomimetic Total Knee Implants, The journal of knee surgery, Vol. 28, No. 5 (2015b), pp. 363-369, DOI: $10.1055 / \mathrm{s}-0035-1551834$.

Vasu, R., Carter, D. R. and Harris, W. H., Stress distributions in the acetabular region--I. Before and after total joint replacement, Journal of biomechanics, Vol. 15, No. 3 (1982), pp. 155-164.

Vasu, R., Carter, D. R., Schurman, D. J. and Beaupre, G. S., Epiphyseal-based designs for tibial plateau components--I. Stress analysis in the frontal plane, Journal of biomechanics, Vol. 19, No. 8 (1986), pp. 647-662.

Vince, K. G. and Cyran, L. T., Unicompartmental knee arthroplasty: new indications, more complications?, The Journal of arthroplasty, Vol. 19, No. 4 Suppl 1 (2004), pp. 9-16.

Wang, H., Foster, J., Franksen, N., Estes, J. and Rolston, L., Gait analysis of patients with an off-the-shelf total knee replacement versus customized bi-compartmental knee replacement, International orthopaedics, Vol. 42, No. 4 (2018), pp. 805-810, DOI: 10.1007/s00264-017-3622-z.

Watanabe, T., Koga, H., Horie, M., Katagiri, H., Sekiya, I. and Muneta, T., Post-Cam Design and Contact Stress on Tibial Posts in Posterior-Stabilized Total Knee Prostheses: Comparison Between a Rounded and a Squared Design, The Journal of arthroplasty, Vol. 32, No. 12 (2017), pp. 3757-3762, DOI: 10.1016/j.arth.2017.07.010.

Wen, P. F., Guo, W. S., Gao, F. Q., Zhang, Q. D., Yue, J. A., Cheng, L. M. and Zhu, G. D., Effects of Lower Limb Alignment and Tibial Component Inclination on the Biomechanics of Lateral Compartment in Unicompartmental Knee Arthroplasty, Chinese medical journal, Vol. 130, No. 21 (2017), pp. 2563-2568, DOI: 10.4103/03666999.217076.

Westrich, G. H., Haas, S. B., Insall, J. N. and Frachie, A., Resection specimen analysis of proximal tibial anatomy based on 100 total knee arthroplasty specimens, The Journal of arthroplasty, Vol. 10, No. 1 (1995), pp. 47-51.

White, P. B. and Ranawat, A. S., Patient-Specific Total Knees Demonstrate a Higher Manipulation Rate Compared to "Off-the-Shelf Implants", The Journal of arthroplasty, Vol. 31, No. 1 (2016), pp. 107-111, DOI: 10.1016/j.arth.2015.07.041.

Willing, R. and Kim, I. Y., Three dimensional shape optimization of total knee replacements for reduced wear, Structural and Multidisciplinary Optimization, Vol. 38, No. 4 (2008), pp. 405-414, DOI: https://doi.org/10.1007/s00158-0080281-0

Willing, R. and Kim, I. Y., Quantifying the competing relationship between durability and kinematics of total knee replacements using multiobjective design optimization and validated computational models, Journal of biomechanics, Vol. 45, No. 1 (2012), pp. 141-147, DOI: 10.1016/j.jbiomech.2011.09.008.

Worland, R. L., Jessup, D. E. and Johnson, J., Posterior cruciate recession in total knee arthroplasty, The Journal of arthroplasty, Vol. 12, No. 1 (1997), pp. 70-73.

Zeller, I. M., Sharma, A., Kurtz, W. B., Anderle, M. R. and Komistek, R. D., Customized versus Patient-Sized CruciateRetaining Total Knee Arthroplasty: An In Vivo Kinematics Study Using Mobile Fluoroscopy, The Journal of 
arthroplasty, Vol. 32, No. 4 (2017), pp. 1344-1350, DOI: 10.1016/j.arth.2016.09.034.

Zhao, D., Sakoda, H., Sawyer, W. G., Banks, S. A. and Fregly, B. J., Predicting knee replacement damage in a simulator machine using a computational model with a consistent wear factor, Journal of biomechanical engineering, Vol. 130, No. 1 (2008), pp. 011004, DOI: 10.1115/1.2838030.

Zhu, G. D., Guo, W. S., Zhang, Q. D., Liu, Z. H. and Cheng, L. M., Finite Element Analysis of Mobile-bearing Unicompartmental Knee Arthroplasty: The Influence of Tibial Component Coronal Alignment, Chinese medical journal, Vol. 128, No. 21 (2015), pp. 2873-2878, DOI: 10.4103/0366-6999.168044.

Zumbrunn, T., Duffy, M. P., Rubash, H. E., Malchau, H., Muratoglu, O. K. and Varadarajan, K. M., ACL substitution may improve kinematics of PCL-retaining total knee arthroplasty, Knee Surgery, Sports Traumatology, Arthroscopy, Vol. 26, No. 5 (2018), pp. 1445-1454, DOI: 10.1007/s00167-016-4372-y.

Zumbrunn, T., Varadarajan, K. M., Rubash, H. E., Malchau, H., Li, G. and Muratoglu, O. K., Regaining Native Knee Kinematics Following Joint Arthroplasty: A Novel Biomimetic Design with ACL and PCL Preservation, The Journal of arthroplasty, Vol. 30, No. 12 (2015), pp. 2143-2148, DOI: 10.1016/j.arth.2015.06.017. 